This is an electronic reprint of the original article. This reprint may differ from the original in pagination and typographic detail.

Author(s): Chun, Hee-Joon; Apaja, Vesa; Clayborne, Andre; Honkala, Karoliina; Greeley, Jeffrey

Title: $\quad$ Atomistic Insights into Nitrogen-Cycle Electrochemistry : A Combined DFT and Kinetic Monte Carlo Analysis of NO Electrochemical Reduction on Pt(100)

Year: $\quad 2017$

Version:

Please cite the original version:

Chun, H.-J., Apaja, V., Clayborne, A., Honkala, K., \& Greeley, J. (2017). Atomistic Insights into Nitrogen-Cycle Electrochemistry : A Combined DFT and Kinetic Monte Carlo Analysis of NO Electrochemical Reduction on Pt(100). ACS Catalysis, 7(6), 38693882. https://doi.org/10.1021/acscatal.7b00547

All material supplied via JYX is protected by copyright and other intellectual property rights, and duplication or sale of all or part of any of the repository collections is not permitted, except that material may be duplicated by you for your research use or educational purposes in electronic or print form. You must obtain permission for any other use. Electronic or print copies may not be offered, whether for sale or otherwise to anyone who is not an authorised user. 
Article

Subscriber access provided by JYVASKYLAN UNIV

Atomistic Insights into Nitrogen-Cycle Electrochemistry: A Combined DFT and Kinetic Monte Carlo Analysis of NO Electrochemical Reduction on $\mathrm{Pt}(100)$

Hee-Joon Chun, Vesa Apaja, Andre Clayborne, Karoliina Honkala, and Jeffrey Greeley

ACS Catal., Just Accepted Manuscript • DOI: 10.1021/acscatal.7b00547 • Publication Date (Web): 17 Apr 2017

Downloaded from http://pubs.acs.org on April 26, 2017

\section{Just Accepted}

"Just Accepted" manuscripts have been peer-reviewed and accepted for publication. They are posted online prior to technical editing, formatting for publication and author proofing. The American Chemical Society provides "Just Accepted" as a free service to the research community to expedite the dissemination of scientific material as soon as possible after acceptance. "Just Accepted" manuscripts appear in full in PDF format accompanied by an HTML abstract. "Just Accepted" manuscripts have been fully peer reviewed, but should not be considered the official version of record. They are accessible to all readers and citable by the Digital Object Identifier (DOI®). "Just Accepted" is an optional service offered to authors. Therefore, the "Just Accepted" Web site may not include all articles that will be published in the journal. After a manuscript is technically edited and formatted, it will be removed from the "Just Accepted" Web site and published as an ASAP article. Note that technical editing may introduce minor changes to the manuscript text and/or graphics which could affect content, and all legal disclaimers and ethical guidelines that apply to the journal pertain. ACS cannot be held responsible for errors or consequences arising from the use of information contained in these "Just Accepted" manuscripts. 


\title{
Atomistic Insights into Nitrogen-Cycle Electrochemistry: A Combined DFT and Kinetic Monte Carlo Analysis of NO Electrochemical Reduction on $\operatorname{Pt}(100)$
}

\author{
Hee-Joon Chun, ${ }^{\dagger}$ Vesa Apaja, ${ }^{\ddagger}$ Andre Clayborne, ${ }^{\S}$ Karoliina Honkala, , and Jeffrey Greeley*† \\ †School of Chemical Engineering, Purdue University, 480 Stadium Mall Drive, West Lafayette, IN 47907 (USA) \\ ${ }^{\dagger}$ Department of Physics, Nanoscience Center, University of Jyväskylä, P.O.Box 35, FI-40014 Jyväskylä, Finland \\ ${ }^{\S}$ Department of Chemistry, University of Missouri-Kansas City, 5110 Rockhill Road, Kansas City, MO (USA) \\ 'Department of Chemistry, Nanoscience Center, University of Jyväskylä, P.O.Box 35, FI-40014 Jyväskylä, Finland
}

\begin{abstract}
Electrocatalytic denitrification is a promising technology for the removal of $\mathrm{NO}_{\mathrm{x}}$ species in groundwater. However, a lack of understanding of the molecular pathways that control the overpotential and product distribution have limited the development of practical electrocatalysts, and additional atomic-level insights are needed to advance this field. Adsorbed $\mathrm{NO}$ has been identified as a key intermediate in the $\mathrm{NO}_{\mathrm{x}}$ electroreduction network, and the elementary steps by which it decomposes to $\mathrm{NH}_{4}{ }^{+}, \mathrm{N}_{2}, \mathrm{NH}_{2} \mathrm{OH}$, or $\mathrm{N}_{2} \mathrm{O}$ remain a subject of debate. Herein, we report a combined Density Functional Theory (DFT) and kinetic Monte Carlo (kMC) study of this reaction on $\operatorname{Pt}(100)$, a catalytic surface that is known to be active for the activation of strong covalent bonds, in acidic electrolytes. This approach describes the effects of coverage-dependent adsorbate-adsorbate interactions, water-mediated protonation kinetics and thermodynamics, and transient potential sweeps, on reaction rates and selectivities. The results predict NO stripping curves in excellent agreement with experiments while, at the same time, providing a mechanistic interpretation of observed current peaks. Further, production of $\mathrm{NH}_{4}{ }^{+}$products is traced to the rapid kinetics of $\mathrm{N}-\mathrm{O}$ bond breaking in reactive intermediates, while rapid hydrogenation of surface $\mathrm{N}^{*}$ species prevent competing pathways from forming either $\mathrm{N}_{2}$ or $\mathrm{N}_{2} \mathrm{O}$. The combined DFT-kMC methodology thus provides a unique tool to describe the mechanism and energetics of platinum-catalyzed electroreduction in the nitrogen cycle, and this approach should also find application to related electrocatalytic processes that are of technological and environmental interest.
\end{abstract}

KEYWORDS: NO electroreduction, Pt(100), electrocatalysis, density functional theory, kinetic Monte Carlo 


\section{Introduction}

Nitrogen can be transformed through both biological and physical processes within the nitrogen cycle to form a broad spectrum of inorganic compounds, including ammonium $\left(\mathrm{NH}_{4}{ }^{+}\right)$, hydrazine $\left(\mathrm{N}_{2} \mathrm{H}_{4}\right)$, hydroxylamine $\left(\mathrm{NH}_{3} \mathrm{OH}^{+}\right)$, nitrite $\left(\mathrm{NO}_{2}{ }^{-}\right)$, nitrate $\left(\mathrm{NO}_{3}{ }^{-}\right)$, nitric oxide (NO), and nitrous oxide $\left(\mathrm{N}_{2} \mathrm{O}\right) .{ }^{1-2}$ While many of these processes are essential to life, large-scale commercial food production has led to overfertilization and consequent accumulation of nitrate and nitrite ions groundwater and in agricultural runoff streams..$^{2-4}$ Both nitrate and nitrite ions are a source of pollution in groundwater, lakes, and coastal water, and they can cause serious health problems, such as methemoglobinemia and cancer, when ingested in high concentrations. As a result, groundwater treatments to reduce the concentration of these ions have been developed and have become an important environmental consideration. ${ }^{3-4}$

Electrochemical denitrification is a promising technology for the removal of $\mathrm{NO}_{\mathrm{x}}$ species from groundwater and constitutes a plausible alternative to traditional denitrification methods, such as biological and physical separations processes, due to its environmental compatibility, energy efficiency, safety, product selectivity, and potential for use in smaller scale devices. ${ }^{3-}$

${ }^{15}$ Nitrate and nitrite electroreduction can produce a variety of products, such as $\mathrm{NO}, \mathrm{N}_{2} \mathrm{O}, \mathrm{N}_{2}$, $\mathrm{NH}_{3} \mathrm{OH}^{+}$and $\mathrm{NH}_{4}{ }^{+15-17}$ However, $\mathrm{NO}$ is proposed to be a key intermediate species that determines product selectivity and influences the overall rate of reaction. ${ }^{3-4}$ Hence, studying low temperature electrocatalytic NO reduction is a first step towards understanding the fundamentals of $\mathrm{NO}_{2}{ }^{-} / \mathrm{NO}_{3}{ }^{-}$electrochemistry and developing improved electrochemical denitrification technologies, and fundamental insights into the reaction chemistry are needed to accelerate these technological developments. In addition, the study of NO electrochemistry is of fundamental scientific interest because observations and developed methods can be straightforwardly applied to other environmentally friendly electrocatalytic reduction 
chemistries. Indeed, as we will show, the electrochemistry of NO has numerous analogies to $\mathrm{CO}_{2}$ electroreduction, which is currently being studied by many research groups. ${ }^{18-22}$

NO electroreduction has been studied under a variety of electrochemical reaction conditions, including reactions on different metal electrodes, ${ }^{7}, 12,23-26$ varying NO concentrations, ${ }^{11,27}$ and different liquid phase electrolytes. ${ }^{23}$ This surface reaction has a rich chemistry and contains numerous reaction steps and intermediates. Thermodynamically, the most favorable product is $\mathrm{N}_{2}$; in electrochemical experiments, however, other products, such as $\mathrm{NH}_{4} \mathrm{OH}^{+}, \mathrm{NH}_{4}^{+}$, and $\mathrm{N}_{2} \mathrm{O},{ }^{7,9-11,28}$ are generally observed. On platinum, in particular,

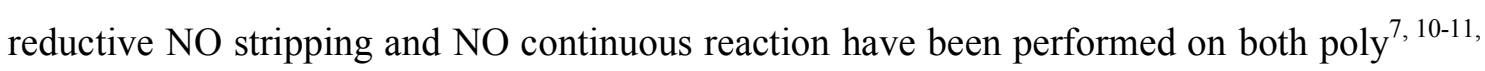
13, 28-29 and single crystalline Pt electrodes $3,9,14,23-24,27$ using cyclic voltammetry (CV). Generally, these CV experiments demonstrated an onset potential of ca. $0.4 \mathrm{~V}_{\mathrm{SHE}}$, with exclusively $\mathrm{NH}_{4}{ }^{+}$production from NO stripping using single crystalline $\mathrm{Pt}$, and $\mathrm{NH}_{4}{ }^{+}$and $\mathrm{N}_{2} \mathrm{O}$ from continuous reduction of $\mathrm{NO}$ using polycrystalline Pt. It has also been observed that the $\operatorname{Pt}(111)$ surface, which has been analyzed by both experiments and theory, ${ }^{9,23,27,30}$ shows high activity for the conversion of NO to ammonia in acid electrolytes. Recently, our group has studied the NO reduction mechanism in acid electrolyte on the single crystal $\mathrm{Pt}(111)$ surface using periodic, self-consistent density functional theory calculations (DFT), ${ }^{30}$ wherein we illustrated that both $\mathrm{NH}_{4}^{+}$and $\mathrm{N}_{2} \mathrm{O}$ could be produced on $\mathrm{Pt}(111)$ through a series of water-assisted protonation steps at different potentials.

In addition to the (111) orientation, $\mathrm{Pt}(100)$ has attracted attention for NO electroreduction studies. ${ }^{3-4,17,24,31-32}$ Rosca et. al. studied NO stripping on the $\operatorname{Pt}(100)$ electrode in acid electrolyte and showed that $\mathrm{NH}_{4}{ }^{+}$was the only observed product. ${ }^{24}$ Based on a combination of the Tafel slope analysis and the fact that HNO is more energetically stable than $\mathrm{NOH}$ in the gas phase, the authors proposed that the reactions occurred via an adsorbed 
HNO intermediate, in which the first proton and electron transfer is in equilibrium (Equation 1), while the second reaction step, corresponding to chemical $\mathrm{N}-\mathrm{O}$ bond cleavage in adsorbed $\mathrm{HNO}$, is the rate determining step (Equation 2). Reduction of adsorbed $\mathrm{NH}^{*}$ and $\mathrm{O}^{*}$ with protons and electrons is then assumed to be rapid (Equations 3-4). The overall reaction is shown in Equation 5.

$$
\begin{gathered}
\mathrm{NO}^{*}+\mathrm{H}^{+}+\mathrm{e}^{-}=\mathrm{HNO}^{*} \\
\mathrm{HNO}^{*}+* \rightarrow \mathrm{HN}^{*}+\mathrm{O}^{*} \\
\mathrm{HN}^{*}+3 \mathrm{H}^{+}+2 \mathrm{e}^{-} \rightarrow \mathrm{NH}_{4}^{+}+* \\
\mathrm{O}^{*}+2 \mathrm{H}^{+}+2 \mathrm{e}^{-} \rightarrow \mathrm{H}_{2} \mathrm{O}+* \\
\text { Overall: } \mathrm{NO}^{*}+6 \mathrm{H}^{+}+5 \mathrm{e}^{-} \rightarrow \mathrm{NH}_{4}^{+}+\mathrm{H}_{2} \mathrm{O}+*
\end{gathered}
$$

Interestingly, their results also suggested that reduction on $\operatorname{Pt}(100)$ might involve a different reaction mechanism compared to $\mathrm{Pt}(111)$ and could yield different products ${ }^{24}$; indeed, on $\mathrm{Pt}(111)$, the electroreduction of $\mathrm{NO}$ forms $\mathrm{NH}_{4}{ }^{+}$and $\mathrm{N}_{2} \mathrm{O}$ as products in acidic media. $^{9,30}$ This result is intriguing for two reasons. First, it is often the case that bond formation, in this case N-N bonds, can occur with lower overbarriers on the square lattice of the (100) surface as compared to the hexagonal (111) surface. ${ }^{33-35}$ Second, Duca and coworkers showed that $\mathrm{N}_{2}$ is a product of nitrate reduction through the $\mathrm{NO}^{*}$ intermediate on the $\operatorname{Pt}(100)$ surface in alkaline media. ${ }^{36}$ Those authors also proposed that the structure sensitivity is critical for the formation of $\mathrm{N}_{2}$ via reaction of $\mathrm{NO}^{*}+\mathrm{NH}_{2} *$.

The experimental observations for NO electroreduction, described above, suggest that this reaction is highly structure sensitive and that important differences in elementary reaction mechanisms exist on $\operatorname{Pt}(111)$ and $\operatorname{Pt}(100)$. Further, the mechanistic understanding on the 
$\operatorname{Pt}(100)$ surface, in particular, is far from complete. A detailed atomistic investigation using density functional theory (DFT), in turn, can not only provide insight into the precise thermochemical details of the mechanism, but can also shed light on key potential-dependent protonation steps and intermediates along the NO electroreduction pathway. In our previous study on the $\operatorname{Pt}(111)$ surface, we illustrated how both the thermodynamics and potentialdependent protonation, through a series of water-assisted hydrogen shuttling steps, play a key role in NO electroreduction. ${ }^{30}$ These effects are also expected to play an important role on $\operatorname{Pt}(100)$, but in addition, coverage-dependent interactions could have a substantial impact on the (100) results, given the strong binding of NO to this surface. To describe all of these interlocking effects, a simulation that takes into account coverage-dependent interactions, activation barriers, and potential-dependent energetics in real time would be highly desirable.

To treat the phenomena described above with as much accuracy as possible, we have implemented a first principles-based kinetic Monte Carlo (kMC) approach. kMC can simulate (electro)chemical processes in real time, taking into account rare reaction events, and the method may be parametrized by data, including adsorption energies and kinetic barriers, obtained from DFT calculations. Further, adsorbate-adsorbate interactions can be explicitly included in Monte Carlo simulations and provide a detailed and nuanced view of a reaction mechanism. The use of combined DFT and equilibrium Monte Carlo simulations has provided insight into various reaction processes, including carbon monoxide ${ }^{37}$ and water ${ }^{38}$ electrooxidation, reduction of surface oxide, ${ }^{39}$ and ammonia synthesis in heterogeneous catalytic reactions. $^{40}$ Limited studies have also demonstrated the power of DFT-kMC when applied to catalysis at gas-solid interfaces ${ }^{41}$ and have shown promise for combining DFT and microkinetic methods in selected electrocatalytic applications. ${ }^{42-44}$ However, there have not, to our knowledge, been any studies that merge DFT and kMC to probe electrocatalytic 
processes.

The combined DFT and kMC approach provides an unprecedentedly detailed picture of the interplay between thermodynamics and kinetics, as well as precise predictions of the current and voltages for NO electroreduction as a function of the applied electrochemical potential. The method thus provides new mechanistic insights into this environmentallycritical chemistry and also permits a direct one-on-one comparison to existing experimental results. Below, we begin by presenting free energies and kinetic barriers from DFT calculations for all relevant elementary reaction steps on $\operatorname{Pt}(100)$. Next, we use the potential-dependent kMC method to produce rigorous kinetic simulations of the reaction current distributions. We compare our results to experiments, and close by highlighting the unique insights to emerge from the synergistic relationship between the DFT and kMC analyses.

\section{Computational methods}

\subsection{Electronic structure calculations}

The calculations are performed within the framework of periodic Density Functional Theory with the Vienna ab-initio simulation package (VASP). ${ }^{45-48}$ The energies and geometries of the most stable configurations on the Pt surfaces are obtained through minimization of the total energy with respect to the geometry by the spin polarized generalized gradient approximation (GGA- PBE). ${ }^{49}$ The projected augmented wave (PAW)

method is used to account for the effect of core electrons on the valence electron density. ${ }^{50}$ The PBE-calculated lattice constant of $3.982 \AA$ for Pt is employed. The $\operatorname{Pt}(100)$ surface is represented by a $3 \times 3$ unit cell with five Pt layers (total of 45 atoms per unit cell). 
Furthermore, a vacuum equivalent to seven Pt layers separates any two successive slabs of Pt atoms. Surface relaxation is allowed in the top three layers of the (100) slab. A planewave energy cutoff of $400 \mathrm{eV}$ is used in these calculations. A minimum k-point grid sampling of 4 $\times 4 \times 1$ is employed. The electronic occupancies are determined according to a MethfesselPaxton scheme with an energy smearing of $0.2 \mathrm{eV}$. The dipole correction is used in all cases to decouple the electrostatic interaction between the periodically repeated slabs. Structures are fully relaxed until the Hellmann-Feynman forces acting on the atoms are smaller than $0.05 \mathrm{eV} / \AA{ }^{30}$

Adsorption and reaction free energies are calculated by correcting the DFT energies for zero-point energies and entropies via

$$
\Delta G=\Delta E+\Delta Z P E+T \Delta S
$$

where $\triangle \mathrm{E}$ is the DFT energy and $\triangle \mathrm{ZPE}$ is the change in zero-point energy of the adsorbates. $\Delta \mathrm{S}$ of $\mathrm{NO}$ adsorption is approximated from the loss of total entropy of the gas phase NO molecules upon binding to the surface. For $\left(\mathrm{H}^{+}+\mathrm{e}^{-}\right)$, the chemical potential at $\mathrm{pH}=0$ is related to the chemical potential of 1 bar of $\mathrm{H}_{2}$ in the gas phase at $298 \mathrm{~K}$ using the standard hydrogen electrode concept $^{51}$; when proton/electron pairs are consumed in elementary reactions, it is assumed that their entire entropy is lost. Entropy of $\mathrm{NO}(\mathrm{g})$ and $\mathrm{H}_{2}(\mathrm{~g})$ are, in turn, taken from thermodynamic tables at $298 \mathrm{~K}(0.65 \mathrm{eV}$ for $\mathrm{NO}(\mathrm{g}), 0.40 \mathrm{eV}$ for $\left.\mathrm{H}_{2}(\mathrm{~g})\right) .{ }^{52}$ Corrections to surface adsorbate energies from hydrogen bonding effects are applied, as discussed in a previous study. ${ }^{30}$ Reaction barriers for $\mathrm{N}-\mathrm{O}$ bond dissociation and protonation of intermediates are modeled within a $3 \times 3$ unit cell and determined using the climbing image nudged elastic band method (CI-NEB) implemented by Henkelman and co- 
workers. ${ }^{53}$ A hydrogen shuttling model is employed for protonation barrier calculations. ${ }^{18,30}$ This approach assumes a symmetry factor of $1 / 2$, implying that transition states possess both initial and final state character. Additional details of the protonation barrier calculations are provided in the Supporting Information.

\subsection{Kinetic Monte Carlo}

Kinetic Monte Carlo (kMC) is an event-based simulation method, where events (surface reactions) occur at prescribed times and trigger follow-up events. The underlying molecular dynamics has inherently atomic time scales of less than a picosecond, while in a simulation we seek to reach timescales of seconds. The purpose of kMC is to overcome these disparate time scales by ignoring the fine details of the molecular dynamics and assuming that reactants have essentially forgotten their past at the time they react.

At the atomic time scale, reactions, which are of primary interest, can be quite rare events, and $\mathrm{kMC}$ moves from reaction to reaction without following every molecular vibration. $\mathrm{kMC}$ also uses a discretized model of the surface, where molecules are located on labelled sites rather than in continuous spatial locations. This reduces the phase space considerably and speeds up the simulation. kMC solves stochastically the master equation

$$
\frac{d P(S)}{d t}=\sum_{S^{\prime}}\left[P\left(S^{\prime}\right) W\left(S^{\prime} \rightarrow S\right)-P(S) W\left(S \rightarrow S^{\prime}\right)\right]
$$

which describes how $P(S)$, the probability of a surface state $S$, depends on time, given that the probability that the surface is in state $S^{\prime}$ is $P\left(S^{\prime}\right)$, and the rate constant of the reaction that changes the surface from state $S$ to $S^{\prime}$ is $W\left(S \rightarrow S^{\prime}\right)$. In words, equation 7 states that $P(S)$ is increased by probability flow to the state $S$ from any other state $S^{\prime}$ (the first term in the sum) 
and is decreased by probability flow from the state $S$ to any other state $S$ ' (the second term in the sum). The master equation can be solved with the First Reaction Method. ${ }^{54}$ One lists all reactions that are possible at a given moment and samples the time a certain reaction will occur from the probability distribution of the reaction times. This probability distribution, in turn, depends on the reaction rate constants. One then picks from the list the reaction that would occur first and allows it to happen. Time is advanced to the time of that reaction, and all new reactions that have now become possible are added to the list of pending reactions. The process is repeated to achieve the desired total simulation time.

Clearly, the correctness of kMC simulation results relies on the correctness of the reaction rate constants (in our case, these are determined by transition state theory and DFT calculations), on the prefactors of the reaction probabilities, and on the assumption that all relevant reaction paths are taken into account. The prefactors are challenging to determine accurately from first principles, because they involve calculation of the entropy in molecular vibrations and in site-specific properties, as discussed thoroughly in references ${ }^{55-56}$ In this work, we adopt straightforward approximations for these quantities. For surface reactions, the prefactor is taken as $\mathrm{k}_{\mathrm{B}} \mathrm{T} / \mathrm{h}$, which at $300 \mathrm{~K}$ amounts to $6.2 \times 10^{12} \mathrm{~s}^{-1}$. This prefactor is consistent with the assumption of zero entropy change of activation for surface processes, which is generally a very reasonable approximation. For adsorption/desorption processes, there can be significant entropy changes, and prefactors may hence deviate substantially from these idealized values. It turns out that, given the particular type of NO stripping experiment that we simulate, it is not necessary to determine prefactors for NO adsorption itself. However, such prefactors are needed for reactions of protons with adsorbed species, for reactions of liquid water with adsorbed species, and for product desorption from the surface. For the former two processes, we assume that protons and water have lost all of 
their bulk phase entropy when they reach the surface transition state. For the latter, we used the ammonia formation free energy and corresponding electrochemical potential from experimental results. ${ }^{3}$

NO is the most abundant surface intermediate on the $\operatorname{Pt}(100)$ surface during the voltammetric sweep, and so we account for the effect of NO-adsorbate interactions on the thermodynamics and kinetics of many of the elementary reactions and intermediates. For such analyses, the local environment is represented by the average local coverage computed on a $9 \times 9$ surface site cell. For fast reactions, the local coverage has no time to vary between the time the reaction becomes possible and the time it occurs. In our calculations, NO* protonation and the reverse deprotonation are both fast, and we have included a dependence on $\mathrm{NO}^{*}$ coverage to the reaction rates. This is accomplished by introducing multiple versions of the same reaction, each with a different reaction rate constant valid for a certain local NO* coverage. Which one of the reactions is actually occurring is decided upon comparing the true local $\mathrm{NO}^{*}$ coverage at that time and the coverage the particular reaction assumed. For fast reactions this is quite accurate, and gives enough resolution to the coverage dependence of NO* protonation and deprotonation. Treatment of adsorbate-adsorbate interactions for slow reactions, such as $\mathrm{NH}_{2}{ }^{*}$ protonation, is more challenging. Since we find that this reaction is, indeed, kinetically significant, we have included the $\mathrm{NH}_{2}{ }^{*}$ protonation coverage dependence in an approximate manner by using multiple reactions, one for each local NO* and $\mathrm{NH}_{2} *$ coverage and the corresponding (constant) reaction rate. This approach is further discussed in the Supporting Information.

We note that, in kMC simulations, very fast reactions (with low barriers) are impractical to follow. In our case, the protonation and deprotonation of NO, which occur even at relatively high voltages, are indeed fast, and they cannot be rigorously simulated considering 
that, for a sweep rate of $5 \mathrm{mV} / \mathrm{s}$, the sweep requires $100 \mathrm{~s}$, and an enormous number of these fast reactions would have occurred within this time period. This problem can be overcome, as described by Jansen, ${ }^{54}$ because the protonation and deprotonation of NO serve to maintain equilibrium on the surface. The principle is to slow down the equilibrium-maintaining fast reaction, making sure it is still fast enough to keep the same coverages of $\mathrm{NO}^{*}, \mathrm{NOH}^{*}$, and the competing intermediate, $\mathrm{HNO}^{*}$. In our simulations we increased the transition state energy to $0.10 \mathrm{eV}$ above the DFT value, which was found to sufficiently speed up the kMC simulation while having converged coverages with respect to even larger increases in the transition state energy (see the Supporting Information for more details).

\section{Results}

We begin by presenting periodic DFT results for the elementary reaction thermodynamics and kinetics of $\mathrm{NO}$ electroreduction on $\mathrm{Pt}(100)$. We then report predicted currents and polarization curves, as determined by $\mathrm{kMC}$. Finally, we discuss kinetically relevant pathways determined by the two methods.

\subsection{Results from DFT calculations}

Below, we first present the configurations of intermediates on the $\operatorname{Pt}(100)$ surface at low and high coverages. Next, we analyze the reaction energies leading to ammonia formation at low and saturated NO coverages. Finally, an analysis of the energetics of $\mathrm{N}_{2}$ and $\mathrm{N}_{2} \mathrm{O}$ is reported.

\subsubsection{Geometry of Intermediates on Pt(100)}


The lowest-energy geometries intermediates leading to both $\mathrm{NH}_{4}{ }^{+}, \mathrm{N}_{2}$, and $\mathrm{N}_{2} \mathrm{O}$ are evaluated at both low and high NO coverages (0.11 ML and $0.55 \mathrm{ML}$ respectively). Figure 1 shows the molecular configurations of each possible intermediate at 0.11 ML (see Supporting Information for corresponding configurations at $0.55 \mathrm{ML}$ and adsorption energetics). At both low and high NO coverages, NO is adsorbed on the bridge site with its molecular axis normal to the surface, which is in agreement with previous DFT studies. ${ }^{57,58}$ Further, $\mathrm{NOH}^{*}$ and $\mathrm{HNOH}^{*}$ prefer adsorption on the bridge site, with the $\mathrm{H}$ bound to the oxygen pointing towards the metal surface. Interestingly, the most stable configuration for HNO* differs at low and high coverages. At low coverages, $\mathrm{HNO}^{*}$ resides in a horizontal geometry on two bridge sites. However, at higher coverages, HNO* is bound to only one bridge site through the nitrogen atom, similar to $\mathrm{HNOH}^{*}$. At low coverages, this tilted HNO* configuration, in which the $\mathrm{N}-\mathrm{O}$ bond is quasi-perpendicular to the surface, is $\sim 0.4 \mathrm{eV}$ higher in energy compared to the horizontal configuration (see the Supporting Information for the configuration of the tilted $\mathrm{HNO}^{*}$ ). In contrast to these other intermediates, $\mathrm{H}_{2} \mathrm{NO}^{*}$ and $\mathrm{H}_{2} \mathrm{NOH}^{*}$ are not bound to bridge sites, but reside on top sites at all coverages.

In order to form ammonia (as well as $\mathrm{N}_{2} / \mathrm{N}_{2} \mathrm{O}$ ), the intermediates $\mathrm{N}^{*}, \mathrm{NH}^{*}, \mathrm{NH}_{2}{ }^{*}$, and $\mathrm{NH}_{3} *$ play a crucial role. At both low and high coverages, $\mathrm{N}^{*}, \mathrm{NH}^{*}$, and $\mathrm{NH}_{2} *$ are bound to a bridge site, a four-fold site, and a bridge site, respectively, while $\mathrm{NH}_{3} *$ is bound to a top site.

Finally, we examined the NO dimer species, which could act a as precursor state for $\mathrm{N}_{2} \mathrm{O}$ formation. It is found that $\mathrm{NO}$ can only form a trans-dimer species, with the respective $\mathrm{N}-$ O bonds pointing in opposite directions with respect to the surface plane (see the Supporting Information). The $c i s-(\mathrm{NO})_{2}$ species is not observed because geometry optimization of this structure yields two separated species at adjacent sites, and no bond is formed between the two $\mathrm{N}$ atoms. 


\subsubsection{Ammonia Formation at Low Surface Coverages}

Figure 2(a) summarizes the reaction network for all intermediates, which includes the forward and reverse barriers for protonation and chemical $\mathrm{N}-\mathrm{O}$ dissociation at $0.0 \mathrm{~V}_{\mathrm{SHE}}$. Direct cleavage of the $\mathrm{N}-\mathrm{O}$ bond in $\mathrm{NO}^{*}$ has a barrier of $0.99 \mathrm{eV}$, which suggests that the reaction will be very slow at room temperature. We note, however, that this barrier is considerably lower than the corresponding value on $\operatorname{Pt}(111), 2.30 \mathrm{eV},{ }^{30}$ which agrees well with literature results and which is a first indication of the structure sensitivity of this process. $^{57}$

The first protonation step, $\mathrm{NO}^{*}+\left(\mathrm{H}^{+}+\mathrm{e}^{-}\right) \rightarrow$ products, is of central importance for determining the subsequent steps in the reaction pathway. The protonation barrier for $\mathrm{NOH}^{*}$ formation at $0.0 \mathrm{~V}_{\mathrm{SHE}}$ is $0.31 \mathrm{eV}$ lower than that for the lowest energy configuration of $\mathrm{HNO}^{*}$, which indicates that $\mathrm{NOH}^{*}$ formation is kinetically more favorable than the formation of the HNO* intermediate at low NO* coverages. Analyses of thermodynamics, however, indicate that the adsorption free energy of $\mathrm{HNO}^{*}$ is energetically $0.31 \mathrm{eV}$ more favorable than that of $\mathrm{NOH}^{*}$ with respect to gas phase $\mathrm{NO}$ and proton/electron pairs (see the Supporting Information), implying that formation of the most stable configuration of $\mathrm{HNO}^{*}$, which is bound to the surface through both nitrogen and oxygen, is more thermodynamically favorable than formation of $\mathrm{NOH}^{*}$.

The free energy diagrams for NO reduction at $0.11 \mathrm{ML}$ coverage at $0.0 \mathrm{~V}_{\mathrm{SHE}}$ are given in Figure 2(b). Energetically competitive reaction pathways proceeding through $\mathrm{NOH}^{*}$ are (i): $\mathrm{NO}^{*} \rightarrow \mathrm{NOH}^{*} \rightarrow \mathrm{N}^{*} \rightarrow \mathrm{NH}_{4}^{+}$and (ii): $\mathrm{NO}^{*} \rightarrow \mathrm{NOH}^{*} \rightarrow \mathrm{HNOH}^{*} \rightarrow \mathrm{NH}^{*} \rightarrow \mathrm{NH}_{4}^{+}$. Alternatively, if $\mathrm{NO}^{*}$ is first reduced to $\mathrm{HNO}^{*}$, there are two possibilities for subsequent reaction steps: (1) protonation to $\mathrm{HNOH}^{*}$ (iii)), and (2) chemical dissociation of $\mathrm{HNO}^{*}$ to 
$\mathrm{NH}^{*}$ and $\mathrm{O}^{*}$ (iv)). Both $\mathrm{HNOH}^{*}$ formation and the chemical dissociation barriers are comparable and sufficiently low to be accessible at room temperature. Interestingly, the modestly metastable $\mathrm{HNO}^{*}$ configuration, in which the $\mathrm{N}-\mathrm{O}$ bond is quasi-perpendicular to the surface (Section 3.1.1), reduces the protonation barrier for the $\mathrm{HNO}^{*} \rightarrow \mathrm{HNOH}^{*}$ from 0.26 to $0.09 \mathrm{eV}$ at $0.0 \mathrm{~V}_{\mathrm{SHE}}$. This result, together with the observation that the quasiperpendicular configuration forms via a considerably shorter reaction pathway than the horizontal configuration, suggests that, even at low NO* coverages, the former configuration is kinetically more relevant for further protonation, and this observation is used in all subsequent kMC simulations (see discussion below).

For all pathways that do not cleave $\mathrm{N}-\mathrm{O}$ bonds in $\mathrm{NOH}^{*}$ or $\mathrm{HNO}^{*}$, further hydrogenation results in the formation of the $\mathrm{HNOH}^{*}$ intermediate. Subsequent protoncoupled electron transfer steps lead, in turn, to the formation of $\mathrm{NH}_{4}{ }^{+}$, because the formation of hydroxylamine $\left(\mathrm{H}_{2} \mathrm{NOH}^{*}\right)$ is energetically unfavorable on $\mathrm{Pt}(100)$, and $\mathrm{N}-\mathrm{O}$ bond cleavage becomes energetically competitive with protonation steps before $\mathrm{H}_{2} \mathrm{NOH}^{*}$ is formed (Figure 2(a)).

It is interesting to note that, after $\mathrm{N}-\mathrm{O}$ bond cleavage occurs in the various pathways, the protonation steps $\mathrm{N}^{*} \rightarrow \mathrm{NH}^{*} \rightarrow \mathrm{NH}_{2} *$ proceed with relatively low barriers. However, the protonation barrier for $\mathrm{NH}_{2} *$ reduction is relatively high at low coverages $(1.08 \mathrm{eV})$, implying that this species could be relatively stable on the surface. It is, however, true that the overall activity of $\mathrm{NH}_{2} *$ reduction is related to the coverage of $\mathrm{NH}_{2} *$ and $\mathrm{NO}^{*}$. Table $\mathrm{S} 2$ shows the coverage-dependent barrier for $\mathrm{NH}_{2} *+\left(\mathrm{H}^{+}+\mathrm{e}^{-}\right) \rightarrow \mathrm{NH}_{3} *$ at different $\mathrm{NO}^{*}$ and $\mathrm{NH}_{2} *$ coverages. The barrier decreases as the $\mathrm{NH}_{2} *$ and $\mathrm{NO}^{*}$ coverage increases and becomes accessible at room temperature at $\Theta_{\mathrm{NH}_{2}} \sim 0.4 \mathrm{ML}$.

In the pathways described above, there are at least two probable intermediates, $\mathrm{NOH}^{*}$ and 
HNO*, that may play important roles in the reaction chemistry, ultimately leading to ammonia formation. The energetics of $\mathrm{NOH}^{*}$ and $\mathrm{HNO}^{*}$ indicate that there is a competition between thermodynamic and kinetic effects in determining the most favorable reaction pathway, but, as we discuss further below, DFT by itself is not able to fully adjudicate between these pathways.

\subsubsection{Ammonia Formation at saturated surface coverage}

To understand the influence of the coverage of surface species on the reaction mechanisms, we examined the reactions at a high total surface coverage (NO coverage: $0.44 \mathrm{ML}$, total coverage: $0.55 \mathrm{ML}$ ). This value is consistent with the estimated saturation coverage of NO of $\sim 0.5 \mathrm{ML}$ on $\operatorname{Pt}(100) .{ }^{17,24}$ The possible pathways leading to ammonia formation are quite similar to what is observed in the lower coverage regime (Figure 3). Protonation of the NO on the surface can lead to either $\mathrm{HNO}^{*}$ or $\mathrm{NOH}^{*}$ formation. However, in contrast to the situation in the low coverage regime, $\mathrm{NOH}^{*}$ and $\mathrm{HNO}^{*}$ have similar formation kinetics and thermodynamics. The thermodynamic binding free energy of $\mathrm{HNO}^{*}$ becomes destabilized because, at high surface coverages, it prefers a tilted configuration, with the $\mathrm{N}-\mathrm{O}$ bond oriented quasi-perpendicular to the $\operatorname{Pt}(100)$ surface, over the horizontal configuration that is preferred at lower coverages (see Supporting Information). Further, the kinetic barriers at the higher $(0.55 \mathrm{ML})$ coverage, as shown in Figure 3(a), indicate that protonation is preferred to the chemical dissociation of $\mathrm{N}-\mathrm{O}$ bonds for all intermediates. While the barrier for chemical $\mathrm{N}-\mathrm{O}$ bond breaking in $\mathrm{HNO}^{*}(0.18 \mathrm{eV})$ is lower than the protonation barrier of $\mathrm{HNO}^{*}(0.26$ $\mathrm{eV}$ ) at low coverages, at the saturated coverage, the barrier for $\mathrm{N}-\mathrm{O}$ bond breaking increases to $0.87 \mathrm{eV}$, while the protonation barrier remains low. This result suggests that, while chemical dissociation may be possible at low coverages, at saturated coverages, $\mathrm{N}-\mathrm{O}$ bond 
dissociation through the HNO* intermediate becomes kinetically unfavorable. This significant coverage effect results from the weak binding of the dissociation products at high coverages, which makes it more difficult to reach the transition state for chemical bond breaking. ${ }^{59}$

From both intermediates $\mathrm{NOH}^{*}$ and $\mathrm{HNO}^{*}$, further protonation leads to $\mathrm{HNOH}^{*}$. It should be noted that it is also possible for $\mathrm{NOH}^{*}$ to form $\mathrm{N}^{*}$ and an additional $\mathrm{H}_{2} \mathrm{O}$ molecule, but the barrier $(0.17 \mathrm{eV})$ is slightly higher than the protonation barrier that leads to $\mathrm{HNOH}^{*}$ (essentially $0.0 \mathrm{eV}$ ) at $0.0 \mathrm{~V}_{\mathrm{SHE}}$. After $\mathrm{HNOH}^{*}$ is formed on the surface, the thermodynamic and kinetic data suggest that a combined dissociation and protonation step will form $\mathrm{NH}^{*}$ and an additional $\mathrm{H}_{2} \mathrm{O}$ molecule, as shown in Figure 3. As is the case at low coverages, $\mathrm{NH}^{*}$ can be easily protonated to form $\mathrm{NH}_{2}{ }^{*}$, but $\mathrm{NH}_{2} *$ conversion to $\mathrm{NH}_{3} *$ has a rather large kinetic barrier $(1.08 \mathrm{eV})$. It should be noted, however, that the latter barrier is lower at the saturated coverage $(0.95 \mathrm{eV})$ than at the lower coverages.

Though the combined thermodynamic and kinetic DFT results suggest that electrochemical $\mathrm{NO}^{*}$ hydrogenation could proceed preferentially through both $\mathrm{NOH}^{*}$ and $\mathrm{HNO}^{*}$ at saturated coverage, the precise atomistic picture at both the low and saturated coverages remains unclear. There are at least two probable intermediates that may facilitate $\mathrm{N}-\mathrm{O}$ dissociation, $\mathrm{NOH}^{*}$ and/or $\mathrm{HNO}^{*}$. Alternatively, these species could be protonated to $\mathrm{HNOH}^{*}$, after which electrochemical dissociation may occur. However, once $\mathrm{NH}_{2}{ }^{*}$ is formed, the protonation to form the aqueous ammonia precursor, $\mathrm{NH}_{3}{ }^{*}$, presents a challenge at low to moderate coverages, with a relatively high barrier. All of these factors imply that the NO electroreduction reaction network is governed by a competition between thermodynamic and kinetic factors that, in turn, dependent on adsorbate coverages. Evaluation of the competition between these disparate factors will be discussed below. 


\subsection{4. $\mathrm{N}_{2}$ and $\mathrm{N}_{2} \mathrm{O}$ formation}

In addition to ammonia, two additional products, $\mathrm{N}_{2}$ and $\mathrm{N}_{2} \mathrm{O}$, could be produced during electrochemical reduction via Langmuir-Hinshelwood-type reactions that form an N-N bond between surface intermediates. The possibility of nitrogen bond formation between NO*, which is present at high coverages, and other surface bound intermediates such as NO*, $\mathrm{NOH}^{*}, \mathrm{HNO}^{*}, \mathrm{~N}^{*}$, and $\mathrm{NH}^{*}$, was examined, and we also investigated possible $\mathrm{N}-\mathrm{N}$ bond formation of lower coverage species, such as NOH-NOH*, HNO-HNO*, N-N*, and NH$\mathrm{NH}^{*}$, at the saturated surface coverage. N-N bond formation using even more highly hydrogenated species, such as $\mathrm{HNOH}^{*}$ and $\mathrm{H}_{2} \mathrm{NO}^{*}$, is energetically unfavorable due to steric repulsions, and no stable bond is formed between the two $\mathrm{N}$ atoms.

The free energy analysis and kinetic barriers of all of the aforementioned species are given in Table 1 and Figure 4, respectively. Even though the kinetic barriers are lower than the corresponding barriers on $\mathrm{Pt}(111),{ }^{30}$ the energies of formation of $\mathrm{NO}-\mathrm{NOH}^{*}, \mathrm{~N}_{2} \mathrm{O} *, \mathrm{NO}-\mathrm{NH}^{*}$, and $\mathrm{NOH}-\mathrm{NOH}^{*}$, are thermodynamically uphill (Figure 4), suggesting that formation of these species is unfavorable. However, the free energy analysis suggests that it may be thermodynamically feasible to form $\mathrm{N}_{2}$ and/or $\mathrm{HN}_{-} \mathrm{NH}^{*}$ on the $\operatorname{Pt}(100)$ surface (Figure 4). Similarly, the DFT-determined kinetic barriers (Table 1) for both the $\mathrm{N}^{*}+\mathrm{N}^{*} \rightarrow \mathrm{N}_{2}{ }^{*}$ and $\mathrm{NH}^{*}+\mathrm{NH}^{*} \rightarrow(\mathrm{HN}-\mathrm{NH})^{*}$ are accessible at room temperature. Though the results suggest that $\mathrm{N}_{2}$ could be a product of $\mathrm{NO}$ reduction at the saturated coverage, these species may not be present at sufficiently high coverages to form appreciable quantities of $\mathrm{N}_{2}$-containing species, and kinetic Monte Carlo simulations will, again, be useful to adjudicate between these possibilities.

Finally, we examine the formation of a trans-(NO) $)_{2}$ dimer on the $\mathrm{Pt}(100)$ surface using an 
Eley-Rideal mechanism, which is a dominant reaction for $\mathrm{N}_{2} \mathrm{O}$ on $\mathrm{Pt}(111)$ in continuous reaction (bulk saturated with $\mathrm{NO}$ ) conditions. ${ }^{30}$ Even at the saturated coverages, however, we found that formation of the trans-(NO) 2 dimer on $\operatorname{Pt}(100)$ requires a $1.32 \mathrm{eV}$ kinetic barrier, indicating that this reaction will not occur at room temperature.

\subsection{Kinetic Monte Carlo analysis}

We first describe the voltammetric stripping current profiles determined by combining the DFT-determined rate and equilibrium constants with the kMC simulations. We then show how these profiles change as a function of the initial coverage of $\mathrm{NO}^{*}$ dosed on the $\operatorname{Pt}(100)$ surface, and through comparison of the simulated and experimental profiles, together with analysis of Tafel slopes and likely rate-determining steps, we draw conclusions as to which elementary reaction pathways dominate the stripping process.

We simulate NO stripping experiments, wherein the equilibrium coverage of NO is adsorbed on the catalyst surface at relatively high potential, following which NO is removed from the bulk solution. The voltage is then reduced at a constant rate, and current is generated as the adsorbed NO* is reduced. The resulting current/voltage relationship contains a tremendous amount of information about the reaction mechanism, but such information is difficult to extract without a detailed kinetic model, which is the focus of the present analysis.

To model this process, NO is adsorbed randomly on bridge sites, and accepted or declined based on the energy of forming the NO configuration. This generates physically intuitive initial configurations; for example, energetics prevents NO from sharing a metal atom with too many other NO's, and as a result neither NO clusters nor long chains form on the $\operatorname{Pt}(100)$ surface. Once the NO coverage reaches the prescribed value, the simulation of the voltammetric sweep commences. We note that, in $\mathrm{kMC}$, reactions occur at a future time, 
which is computed from the known reaction rate. In voltammetry, the reaction rate itself is also time dependent, but with a constant sweep rate, this dependence may be determined from analytical solution of the reaction time. ${ }^{60}$

The voltammetric profile is obtained by taking the numerical derivative of the cumulative charge transfer (= charge leaving the surface) averaged over 100 sweeps for the reductive striping of $\mathrm{NO}$ over $\mathrm{Pt}(100)$ for various initial NO coverages. Figure 5 gives the profile at an initial NO* coverage of $0.51 \mathrm{ML}$. The calculated profile highlights two characteristic features: 1) A sharp peak at approximately $0.18 \mathrm{~V}_{\mathrm{SHE}}$, and 2) a broad shoulder at slightly more negative potentials $\left(\sim 0.11 \mathrm{~V}_{\mathrm{SHE}}\right)$. The shapes of the peaks in the calculated profile compares well with the shapes of the experimental peaks, while the simulated peaks are shifted to a slightly more negative potential than the experimentally obtained values. Figure 6 displays the simulated voltammetric response to various initial NO coverages. In line with the measured profiles, the attenuation of the main peak is observed with decreasing initial NO coverage, while the second peak seems to remain largely unchanged in both simulations and measurements. We note that, similar to the measured profile, the simulated profile presents only one broad feature at $0.11 \mathrm{ML}$ initial NO coverage, for which the potential region is from 0.25 to $0.05 \mathrm{~V}_{\mathrm{SHE}}$.

Even though the peak positions agree well with experimentally observed features, the magnitude of current produced at the peak potential is only about $1 / 3$ of the measured value. To shed light on this discrepancy, we calculate the maximum charge transfer possible for this chemistry. If all available $\mathrm{NO}$ eventually protonates to $\mathrm{NH}_{4}{ }^{+}$, then 5 electrons are transferred per NO, which amounts to approximately $516 \mu \mathrm{C} / \mathrm{cm}^{2}$ at $0.51 \mathrm{ML}$ of NO coverage. However, the experimental current by Rosca and Koper $^{24}$ indicates that the total charge transfer is over $800 \mu \mathrm{C} / \mathrm{cm}^{2}$, with the difference from the theoretical maximum perhaps explained by double 
layer capacitance, the charge transfer from proton adsorption during the NO reduction, and defects on the $\operatorname{Pt}(100)$ single crystal surface in experiments. The smaller charge value in our simulation could be related to the reduced maximum current compared to experiment, while residual differences are well within the magnitudes of deviations of rate theory calculations from experiments. ${ }^{61-62}$ Indeed, the simulation contains no adjustable parameters; so a deviation of this magnitude is not surprising. We additionally note that, as shown in Figures S8, S9, and S11 of the Supporting Information and also discussed at the end of Section 3.2, modest changes in reaction barriers or prefactors do not lead to significant changes in current magnitude although they do produce some shifts in the peak potentials.

As discussed above, the DFT calculations imply that the NO electroreduction reaction can follow multiple elementary pathways, and the stripping peaks could thus be a combination of multiple electrochemical and/or chemical steps. The kMC model, in turn, provides a useful strategy for deconvoluting the contributions of the various steps. Once a product $\mathrm{NH}_{4}{ }^{+}$ molecule has formed and leaves the surface, it is possible to trace back the reaction path to NO*. This is done by tagging nitrogen atoms and following their motion in reactions of the surface molecules. Such tagging is simple in simulations, and in experiments, isotopes have been used to the same effect. ${ }^{54}$ The nitrogen path eventually traces back to adsorbed NO*, which is the only source of nitrogen, and this provides one sample of an $\mathrm{NH}_{4}{ }^{+}$formation pathway. With enough such samples, one can reliably extract the probabilities of the various $\mathrm{NH}_{4}{ }^{+}$reaction paths.

We first note that, in our calculations, some $\mathrm{NH}_{2}{ }^{*}$ remained on the surface at the lowest potential of the voltammetry sweep. The buildup of $\mathrm{NH}_{2} *$ on $\mathrm{Pt}(100)$, in turn, originates from the barriers to form $\mathrm{NH}_{3}{ }^{*}$. According to the present calculations, as well as literature, the activation barrier for the hydrogenation of $\mathrm{NH}_{2}{ }^{*}$ to $\mathrm{NH}_{3} *$ is relatively high at low 
coverages. ${ }^{36,63}$ However, the activation energy decreases with increasing $\mathrm{NH}_{2} *$ and/or $\mathrm{NO}^{*}$ coverage (Table S2), and ammonia formation begins when the coverage has reached a sufficiently high value. Nevertheless, at the lowest potentials in our sweep, some $\mathrm{NH}_{2}$ * remains on the surface, and the pathway for this $\mathrm{NH}_{2} *$ formation can be traced in a similar manner to $\mathrm{NH}_{4}{ }^{+}$formation. This approach gave very similar results to that for desorbed $\mathrm{NH}_{4}{ }^{+}$; so we conclude that there is no pathway to produce $\mathrm{NH}_{2} *$ that is not also involved in $\mathrm{NH}_{4}{ }^{+}$ formation.

Table 2 and Figure 7 summarize the most probable pathways for $\mathrm{NH}_{4}^{+}$formation under electrochemical reaction conditions obtained by analyzing several thousand pathways from hundreds of $\mathrm{kMC}$ runs (for a full list all the elementary steps included into the kMC simulations, see Table S2.). In general, the probability and the order of the most probable pathways are independent of the initial $\mathrm{NO}^{*}$ coverage. Two pathways via the $\mathrm{NOH}^{*}$ intermediate clearly dominate, with probabilities $\geq 55 \%$ ("Path 1 ") and $\geq 36 \%$ ("Path 2 "). Indeed, given the sensitivity of these probabilities to small perturbations in activation energies, the pathways could be considered to be equally probable. In Path 1, the formation of $\mathrm{NOH}^{*}$ is followed by the formation of $\mathrm{HNOH}^{*}$, which then dissociates to form $\mathrm{NH}^{*}$ and $\mathrm{H}_{2} \mathrm{O}$. The $\mathrm{NH}^{*}$ is reduced first to $\mathrm{NH}_{2}{ }^{*}$, then $\mathrm{NH}_{3}{ }^{*}$, and finally to $\mathrm{NH}_{4}{ }^{+}$. Path 2 differs from path 1 in that the reduction of $\mathrm{NOH}^{*}$ leads the formation of $\mathrm{N}^{*}$ and $\mathrm{H}_{2} \mathrm{O}(a q)$. While water dissolves into the electrolyte (no water re-adsorption is allowed in our simulations), $\mathrm{N}^{*}$ is reduced in a sequential fashion to $\mathrm{NH}_{4}{ }^{+}$. The third most probable pathway goes via $\mathrm{HNO}^{*}$ but has a probability of only $\sim 5.6 \%$. In this pathway, $\mathrm{HNO}^{*}$ reduces to $\mathrm{HNOH}^{*}$, and thereafter the reaction pathway is identical to that of Path 1, as shown in Figure 7.

In addition to the global pathway analysis described above, we examined the kinetic relevance of all individual elementary steps after the initial reduction step by varying 
transition state energies of the various steps and observing the effect on the simulated voltammetric profiles. In principle, rigorous determinations of kinetic relevance could be made using Campbell's Degree of Rate Control analysis, ${ }^{64}$ but such an approach is not practically useful for the present simulations because of the large uncertainties associated with differentiation of statistical rates. For the analysis, therefore, we selected two elementary steps after $\mathrm{NOH}^{*}$ is formed, $\mathrm{NOH}^{*}+\left(\mathrm{H}^{+}+\mathrm{e}^{-}\right) \rightarrow \mathrm{N}^{*}+\mathrm{H}_{2} \mathrm{O}($ aq $)$ and $\mathrm{NOH}^{*}+\left(\mathrm{H}^{+}+\mathrm{e}^{-}\right) \rightarrow$ $\mathrm{HNOH}^{*}$, corresponding to pathways 1 and 2 (Figure 7 and Table 2), and individually varied their transition state energies by $\pm 0.1 \mathrm{eV}$ and $\pm 0.2 \mathrm{eV}$. As shown in Figures $\mathrm{S} 8$ and S9, decreasing the transition state energies moves both current peaks towards higher voltage values, since the reaction proceeds through the pathway with the lowered barrier and thus requires less overpotential. However, increasing the TS energy of either of the two elementary steps does not alter the peak positions, since the reaction simply shifts to the other parallel pathway. If the barriers of both parallel pathways are simultaneously increased by 0.3 $\mathrm{eV}$, however, the onset potential drops below $0.15 \mathrm{~V}$, and the shape of the curve changes dramatically (Figure $\mathrm{S} 10$ ). In this case, the $\mathrm{NOH}^{*}$ mechanism is completely blocked, and the reaction pathway via $\mathrm{HNO}^{*}$ dominates with a probability of $60 \%$ (in general, the shape of the current peak is typically sharp for $\mathrm{NOH}^{*}$-dominated pathways and broad for $\mathrm{HNO}^{*}$ dominated pathways). However, the fact that a relatively large increase in two barriers is required to shift the reaction mechanism to the HNO* pathway is, in fact, indirect evidence of the robustness and dominance of the $\mathrm{NOH}^{*}$ pathway. This result also demonstrates that modest changes to barriers from approximations made in the barrier calculations are unlikely to affect the mechanistic conclusions (see Section 2.1 and discussion below).

\section{Discussion}




\subsection{Mechanistic Considerations}

In recent years, there has been some debate about whether $\mathrm{HNO}^{*}$ or $\mathrm{NOH}^{*}$ is the first intermediate on the electrode surface during the electrochemical reduction of NO. In the case of $\mathrm{Pt}(111)$, we recently showed that $\mathrm{NOH}^{*}$ is dominant. However, previous experimental studies on the $\operatorname{Pt}(100)$ surface have suggested that $\mathrm{HNO}^{*}$ is the likely first intermediate in the reduction pathway ${ }^{17,24}$ because gas phase $\mathrm{HNO}$ is about $100 \mathrm{~kJ} / \mathrm{mol}$ more stable than gas phase NOH. ${ }^{65}$ Rosca and Koper propose that $\mathrm{HNO}^{*}$ formation is followed by chemical $\mathrm{N}-\mathrm{O}$ dissociation and, ultimately, formation of ammonia. ${ }^{24}$

Free energy analyses provide some insight into preferred mechanistic pathways and may thus partially inform the debate about relevant $\mathrm{NO}$ electroreduction intermediates. If one considers only the free energy results at low adsorbate coverages and assumes that the thermodynamically preferred pathway is dominant, then $\mathrm{HNO}^{*}$ would likely be the preferred intermediate. In a similar fashion, a purely thermodynamic analysis at saturated coverage suggests that both $\mathrm{NOH}^{*}$ and $\mathrm{HNO}^{*}$ are plausible intermediates. When kinetic barriers are also considered, however, the reactivity picture changes somewhat, with DFT results showing that barriers for $\mathrm{HNO}^{*}$ formation are either higher than the corresponding barriers to form $\mathrm{NOH}^{*}$ or, at the highest coverages, comparable, suggesting that $\mathrm{NOH}^{*}$ formation could be kinetically preferred to $\mathrm{HNO}^{*}$ formation. $\mathrm{NOH}^{*}$ can be further reacted via two pathways (1 and 2) with relatively low forward barriers and large reverse barriers at saturated coverages. At these coverages, the barriers for further protonation from $\mathrm{NOH}^{*}$ to $\mathrm{HNOH}^{*}$ or $\mathrm{N}^{*}(0.00$ and $0.17 \mathrm{eV}$, respectively) are lower than corresponding barriers for $\mathrm{HNO}^{*}$ protonation to $\mathrm{HNOH}^{*}(0.26 \mathrm{eV})$, again suggesting that reactivity through $\mathrm{NOH}^{*}$ intermediates is preferred.

Although consideration of free energies suggests plausible NO electroreduction pathways on $\operatorname{Pt}(100)$, the energy differences of competing pathways are sufficiently small that other 
phenomena, such as site blocking and coverage effects, could potentially influence the mechanism. As described above, such effects are explicitly accounted for in the kMC simulations, permitting rigorous comparison of different reaction mechanisms with one another and with experimental data. We observe, for example, that the $\mathrm{NOH}^{*}$-containing pathways (1 and 2 above) produce peaked voltage-current profiles (Figure 5), in excellent agreement with experimental measurements. If, however, the formation of the $\mathrm{NOH}^{*}$ intermediate is hindered by increasing the $\mathrm{NOH}^{*}$ formation barrier in the DFT-kMC analysis, then the reaction is forced to proceed via the $\mathrm{HNO}^{*}$ intermediate, and the predicted voltagecurrent profile becomes very broad and begins to deviate substantially from the experimental results.

The stripping curve shapes, together with the pathway probability analysis described in section 3, clearly suggests that the initial stripping peak at $\sim 0.2 \mathrm{~V}_{\mathrm{SHE}}$ (Figure 5) can be attributed to an electrochemical pathway that involves $\mathrm{NOH}^{*}$ formation and reaction. Similarly, the second peak in Figure 5 appears to be due to delayed $\mathrm{NOH}^{*}$ formation; $\mathrm{NOH}^{*}$ formation increases suddenly as the $\mathrm{NO}^{*}$ coverage decreases, since the activation energy drops from the high coverage $(0.5 \mathrm{ML})$ value, $0.45 \mathrm{eV}$, to the low coverage $(0.3 \mathrm{ML})$ value, $0.39 \mathrm{eV}$ (see Supporting Information). The freshly formed $\mathrm{NOH}^{*}$ then reacts through the entire pathway, and all of these electrochemical steps add up to the second peak in the current. This result was confirmed by repeating the simulations with a coverage independent, average, activation barrier for $\mathrm{NOH}^{*}$ formation, where no second peak was observed.

Given the above considerations, the high voltage peak $\left(0.2 \mathrm{~V}_{\mathrm{SHE}}\right)$ is seen to result from $\mathrm{NOH}^{*}$ formation and conversion, while the second, lower voltage peak in $\mathrm{kMC}$ originates from the coverage-dependent activation energy for $\mathrm{NOH}^{*}$ formation. We note, however, that an alternative explanation has been proposed by Rosca and Koper, ${ }^{24}$ who suggested that the 
second peak is related to the $\mathrm{NO}^{*}$ reduction at different sites such as defects. Our analysis demonstrates that such defect sites are not required to produce a shoulder peak, but we cannot exclude the possibility that defects do contribute to the voltammetric profile (see also discussion below).

The mechanism described above is an "EE" mechanism and consists of two consecutive proton-electron transfer steps that occur after the initial adsorption of nitric oxide. To further elucidate the kinetic features of this pathway, we compute the Tafel slope, which can be determined by plotting the peak position versus the logarithm of the scan rate. ${ }^{66} \mathrm{We}$ directly simulate the peak position by varying the sweep rate and then plotting the peak position as a function of the logarithm of the sweep rate. For each point in the plot, at least $30 \mathrm{kMC}$ simulations are carried out to ensure statistical reliability.

Figure 8 displays the Tafel slope obtained from the kMC simulations. The calculated slope is $41 \mathrm{mV} /$ decade, which is generally interpreted as an EE mechanism, in agreement with our reaction mechanism analysis. This result also suggests that, although it has a relatively high barrier at lower $\mathrm{NH}_{2} *$ coverages, the step $\mathrm{NH}_{2} *+\mathrm{H}^{+}+\mathrm{e}^{-} \rightarrow \mathrm{NH}_{3} *$ is not fully rate-limiting. Indeed, accumulation of $\mathrm{NH}_{2}{ }^{*}$ on the surface rapidly lowers the barrier for further hydrogenation (Figure 3), resulting in additional $\mathrm{NH}_{4}{ }^{+}$production. Some residual $\mathrm{NH}_{2}{ }^{*}$ nevertheless remains on the surface at $\sim 0.05 \mathrm{~V}_{\mathrm{SHE}}$, and this could be removed by further lowering of the potential.

Experiments by Koper and coworkers found a Tafel slope of close to $60 \mathrm{mV} / \mathrm{decade}$, suggesting that an EC mechanism, wherein one protonation step followed by one chemical $\mathrm{N}-\mathrm{O}$ bond breaking step, may be followed. ${ }^{24}$ There are several possible explanations for these slightly different mechanistic interpretations. First, it is possible that the calculated protonation barriers are underestimated using only a single water molecule; including more 
water molecules, with structures such as the well-known ice-like water bilayer ${ }^{67}$ or liquid water, ${ }^{68}$ can increase the protonation barriers, because the additional energy is required for breaking the hydrogen bonds in adjacent water layers. ${ }^{30}$ Alternatively, it is possible that a lower barrier for chemical dissociation of $\mathrm{NOH}^{*}$ could promote the EC pathway. It is possible to test this hypothesis in the $\mathrm{kMC}$ model by manually decreasing the $\mathrm{NOH}^{*}$ chemical dissociation barrier. We find that the EC mechanism becomes preferred when the corresponding barrier is around $0.2 \mathrm{eV}$ lower than the DFT value (see the details in the Supporting Information). Such a lowering of the dissociation barrier could be accomplished on steps or other defects. It is therefore possible that the chemical dissociation in experiments could occur on defects on the $\operatorname{Pt}(100)$ surface, which may form when the square symmetry of the (100) $-1 \times 1$ type surface is reconstructed to form other terminations, such as $5 \times 1$ or hex intermediate phases, under electrochemical reaction conditions. ${ }^{69-70}$

\subsection{Unfavorable formation of $\mathrm{N}_{2}$ and $\mathrm{N}_{2} \mathrm{O}$ on Pt(100) in acid electrolyte}

Although NO stripping experiments on $\operatorname{Pt}(100)$ in acid electrolytes clearly demonstrate that $\mathrm{NH}_{4}^{+}$is the preferred product, it is somewhat surprising that $\mathrm{N}_{2}$ and $\mathrm{N}_{2} \mathrm{O}$ are not formed ${ }^{24}$ since $\operatorname{Pt}(100)$ shows a highly selective conversion to $\mathrm{N}_{2}$ in similar reactions, such as the electrochemical reduction of $\mathrm{NO}_{2}{ }^{-}$, in alkaline solution. ${ }^{32,36,33}$ Although DFT suggests a few thermodynamically and kinetically accessible possibilities for formation of $\mathrm{N}_{2}$, the probabilities for those pathways to form $\mathrm{N}_{2}$ or $\mathrm{N}_{2} \mathrm{O}$ are essentially zero in the kMC simulations. This results directly from the fact that, on the (100) surface, protonation to more hydrogenated species, or rapid dissociation, is energetically preferred to formation N-N bonds. The only exception to this general rule is for $\mathrm{N}^{*}+\mathrm{N}^{*} \rightarrow \mathrm{N}_{2}$, where the activation energy for combination is relatively small. However, this reaction channel is prevented because the 
$\mathrm{N}^{*}$ coverage is low, and two $\mathrm{N}^{*}$ atoms are rarely close enough to each other to form a $\mathrm{N}_{2}$ molecule. Therefore, $\mathrm{N}_{2}$ formation is never observed in the $\mathrm{kMC}$ simulations.

\subsection{Reaction rates and onset potentials}

Using the standard onset potential approach, which has been successfully employed to describe trends in kinetics for several electrocatalytic reactions, including oxygen reduction, ${ }^{71}$ oxygen evolution, ${ }^{72} \mathrm{CO}_{2}$ reduction, ${ }^{18}$ and dimethyl ether oxidation, ${ }^{73}$ the onset potential for NO reduction is expected to be $-0.2 \mathrm{~V}_{\mathrm{SHE}}$, where free energies of all reaction intermediates become downhill relative to $\mathrm{NO}^{*}$ (see the Supporting Information). On the other hand, the $\mathrm{kMC}$ analysis revealed that the corresponding potential is $0.2 \mathrm{~V}_{\mathrm{SHE}}$, which is close to the experimental observations. The explanation for this modest difference in predictions from the two methods is as follows. The standard onset potential approach assumes that the activation barrier for the rate-limiting proton transfer step is equal to the free energy differences at the equilibrium potential without explicitly considering kinetic overbarriers. There is, however, a hidden barrier that is associated with the very low prefactor used in the onset potential analysis; it is about $200 \mathrm{~s}^{-1}$, which is obviously much lower than any physical prefactor can be. ${ }^{51}$ In the kMC analysis, however, the calculated potential-dependant free energy barriers are explicitly determined for the electrochemical hydrogenation steps, and prefactors of $\mathrm{k}_{\mathrm{B}} \mathrm{T} / \mathrm{h}$ are assumed. Based on this approach, it is found that the calculated overbarriers with the $\mathrm{k}_{\mathrm{B}} \mathrm{T} / \mathrm{h}$ prefactor give a reasonable magnitude of reaction rate constants (order of $10^{0} \mathrm{~s}^{-1}$ ) for proton transfer steps at $0.2 \mathrm{~V}_{\mathrm{SHE}}$. To further illustrate this point and to explore the influence of the chosen prefactor on the kMC simulations, we systematically decreased or increased all prefactors by a factor of 10 or 100 and computed new current profiles. Figure S11 in the Supporting Information shows the modified profiles. Decreasing the prefactors moves peak 
positions towards lower voltage values, while increasing the prefactor transfers the peaks towards higher voltage. In particular, reducing the prefactors by a factor of 100 shifts the peak from $0.17 \mathrm{~V}_{\mathrm{SHE}}$ to $0.09 \mathrm{~V}_{\mathrm{SHE}}$, while increasing the prefactors by 100 changes the peak from $0.17 \mathrm{~V}_{\mathrm{SHE}}$ to $0.22 \mathrm{~V}_{\mathrm{SHE}}$ at an initial $\mathrm{NO}^{*}$ coverage of $0.51 \mathrm{ML}$. These $\mathrm{kMC}$ results clearly show that there is a non-negligible reaction flux (the electric current density around 10 $\mu \mathrm{A} / \mathrm{cm}^{2}$ ) at $0.2 \mathrm{~V}_{\mathrm{SHE}}$ (Figure 5), demonstrating that reaction is active at this voltage even though the reaction energy is not formally exothermic at this potential. Therefore, the more detailed approach, as employed in this work, is expected to be useful when there is nonnegligible change of overbarriers with applied potential or when the magnitude of the barriers deviates significantly from what is assumed in the standard onset potential approach. When the DFT calculation of kinetics and kMC with the physical prefactor are taken into account, the similarity to experimental data for the current density as a function of potential is compelling.

\section{Conclusions}

A method of coupling Density Functional Theory and kinetic Monte Carlo studies is developed for electrochemical reactions on transition metal surfaces, and the strategy is applied to NO electroreduction, a chemistry that underlies electrochemical strategies to remove nitrate contaminants from groundwater and agricultural runoff streams. This approach permits direct prediction of the kinetics of all elementary reaction pathways, including the effects of adsorbate-adsorbate interaction energies, and thus allows a direct comparison of theoretical and experimental reactivity data at a level that would not be possible with either method alone. The results indicate that NO electroreduction on $\mathrm{Pt}(100)$, a key catalyst for this chemistry, will occur in the potential range of 0.25 to $0.05 \mathrm{~V}_{\mathrm{SHE}}$, with a 
sharp peak at $\sim 0.2$ and a broad shoulder at $\sim 0.1 \mathrm{~V}_{\mathrm{SHE}}$. Both peaks can be ascribed to NO* reduction to $\mathrm{NH}_{4}{ }^{+}$through adsorbed $\mathrm{NOH}^{*}$ intermediates, with the different peak potentials resulting from changes in the reaction energies as the surface coverage of $\mathrm{NO}^{*}$ is changed during the reduction process. Production of other products, including $\mathrm{N}_{2}$ and $\mathrm{N}_{2} \mathrm{O}$, is minimal due to the rapid kinetics of protonation compared to N-N bond formation. Two protonation pathways via $\mathrm{NOH}^{*}$ dominate the reaction chemistry: 1) $\mathrm{NO}^{*} \rightarrow \mathrm{NOH}^{*} \rightarrow \mathrm{HNOH}^{*} \rightarrow \mathrm{NH}^{*}$ $\rightarrow \mathrm{NH}_{2}{ }^{*} \rightarrow \mathrm{NH}_{3}^{*} \rightarrow \mathrm{NH}_{4}^{+}$and 2) $\mathrm{NO}^{*} \rightarrow \mathrm{NOH}^{*} \rightarrow \mathrm{N}^{*} \rightarrow \mathrm{NH}^{*} \rightarrow \mathrm{NH}_{2}{ }^{*} \rightarrow \mathrm{NH}_{3}^{*} \rightarrow \mathrm{NH}_{4}^{+}$. The simulated Tafel slope for the reaction is $41 \mathrm{mV} / \mathrm{decade}$, which suggests an $\mathrm{EE}$ mechanism for the reaction network.

The mechanistic analyses in this work provide a description of the NO electroreduction network on $\operatorname{Pt}(100)$ at an unprecedented level of detail. This information forms a rigorous basis for future studies that could seek to identify catalysts for the optimization of other products, such as $\mathrm{NH}_{2} \mathrm{OH}$ or $\mathrm{N}_{2}$. The combination of DFT and $\mathrm{kMC}$ methods also provides a powerful strategy to analyzing both atomic-level and macroscopic kinetic features of electrocatalytic processes that should be broadly applicable to the simulation of many environmentally-relevant electrochemical reactions on transition metal catalysts, ultimately leading to the design of more environmentally-friendly electrocatalytic processing strategies.

\section{Supporting Information}

Additional details of DFT calculations (protonation kinetics, geometries for reaction intermediates, and free energy analyses). Additional methodological details and input parameters for kinetic Monte Carlo simulations. 


\section{Author Information \\ Corresponding Author \\ *E-mail: jgreeley@purdue.edu}

\section{Acknowledgments}

J.G. acknowledges a Department of Energy Early Career award through the Office of Science, Office of Basic Energy Sciences, Chemical, Biological, and Geosciences Division. Use of the Center for Nanoscale Materials was supported by the U.S. Department of Energy, Office of Science, Office of Basic Energy Sciences, under Contract DE-AC02-06CH11357. H.C. and J.G. gratefully acknowledge the computing resources provided on Blues and Fusion, a highperformance computing cluster operated by the Laboratory Computing Resource Center at Argonne National Laboratory, as well as the computational resources through the National Energy Research Scientific Computing Center (NERSC). KH acknowledges the financial support from the Academy of Finland (grant 277222). A.C. was previously at the University of Jyväskylä (Finland) and acknowledges financial support from the Academy of Finland (grant 258500). 


\section{References}

1. Canfield, D. E.; Glazer, A. N.; Falkowski, P. G. Science 2010, 330, $192-196$.

2. Galloway, J. N.; Townsend, A. R.; Erisman, J. W.; Bekunda, M.; Cai, Z.; Freney, J. R.; Martinelli, L. A.; Seitzinger, S. P.; Sutton, M. A. Science 2008, 320, 889-892.

3. Rosca, V.; Duca, M.; de Groot, M. T.; Koper, M. T. M. Chem. Rev. 2009, 109, 2209-2244.

4. Duca, M.; Koper, M. T. M. Energy Environ. Sci. 2012, 5, 9726-9742.

5. Bae, S.-E.; Gewirth, A. A. Farad. Discuss. 2008, 140, 113-123.

6. Bae, S.-E.; Stewart, K. L.; Gewirth, A. A. J. Am. Chem. Soc. 2007, 129, 10171-10180.

7. de Vooys, A. C. A.; Beltramo, G. L.; van Riet, B.; van Veen, J. A. R.; Koper, M. T. M. Electrochim. Acta 2004, 49, 1307-1314.

8. Dima, G. E.; de Vooys, A. C. A.; Koper, M. T. M. J. Electroanal. Chem. 2003, 554, 1523.

9. Beltramo, G. L.; Koper, M. T. M. Langmuir 2003, 19, 8907-8915.

10. de Vooys, A. C. A.; Koper, M. T. M.; van Santen, R. A.; van Veen, J. A. R. J. Catal. 2001, 202, 387-394.

11. de Vooys, A. C. A.; Koper, M. T. M.; van Santen, R. A.; van Veen, J. A. R. Electrochim. Acta 2001, 46, 923-930.

12. Alvarez, B.; Rodes, A.; Perez, J. M.; Feliu, J. M.; Rodriguez, J. L.; Pastor, E. Langmuir 2000, 16, 4695-4705.

13. Gootzen, J. F. E.; van Hardeveld, R. M.; Visscher, W.; van Santen, R. A.; van Veen, J. A. R. Recl. Trav. Chim. Pays-Bas 1996, 115, 480-485.

14. Molodkina, E. B.; Botryakova, I. G.; Danilov, A. I.; Souza-Garcia, J.; Figueiredo, M. C.; Feliu, J. M. Russ. J. Electrochem. 2014, 50, 370-378.

15. Figueiredo, M. C.; Solla-Gullón, J.; Vidal-Iglesias, F. J.; Climent, V.; Feliu, J. M. Catal. Today 2013, 202, 2-11.

16. de Groot, M. T.; Koper, M. T. M. J. Electroanal. Chem. 2004, 562, 81-94.

17. Molodkina, E. B.; Botryakova, I. G.; Danilov, A. I.; Souza-Garcia, J.; Feliu, J. M. Russ. J. Electrochem. 2012, 48, 302-315.

18. Nie, X.; Esopi, M. R.; Janik, M. J.; Asthagiri, A. Angew. Chem. Int. Ed. 2013, 52, 24592462.

19. Montoya, J. H.; Peterson, A. A.; Nørskov, J. K. ChemCatChem 2013, 5, 737-742.

20. Shi, C.; O'Grady, C. P.; Peterson, A. A.; Hansen, H. A.; Nørskov, J. K. Phys. Chem. Chem. Phys. 2013, 15, 7114-7122.

21. Hansen, H. A.; Varley, J. B.; Peterson, A. A.; Nørskov, J. K. J, Phys. Chem. Lett. 2013, 4, 388-392.

22. Peterson, A. A.; Abild-Pedersen, F.; Studt, F.; Rossmeisl, J.; Norskov, J. K. Energy Environ. Sci. 2010, 3, 1311-1315.

23. Rosca, V.; Beltramo, G. L.; Koper, M. T. M. Langmuir 2005, 21, 1448-1456.

24. Rosca, V.; Koper, M. T. M. J. Phys. Chem. B 2005, 109, 16750-16759.

25. Yan, Y.-G.; Huang, B.-B.; Wang, J.-Y.; Wang, H.-F.; Cai, W.-B. J. Catal. 2007, 249, 311317. 
26. Rodes, A.; Gomez, R.; Perez, J. M.; Feliu, J. M.; Aldaz, A. Electrochim. Acta 1996, 41, $729-745$

27. Cuesta, A.; Escudero, M. Phys. Chem. Chem. Phys. 2008, 10, 3628-3634.

28. Janssen, L. J. J.; Pieterse, M. M. J.; Barendrecht, E. Electrochim. Acta 1977, 22, 27-30.

29. Nakata, K.; Kayama, Y.; Shimazu, K.; Yamakata, A.; Ye, S.; Osawa, M. Langmuir 2008, 24, 4358-4363.

30. Clayborne, A.; Chun, H. J.; Rankin, R. B.; Greeley, J. Angew. Chem. Int. Ed. 2015, 54, 8255-8258.

31. Li, H.; Calle-Vallejo, F.; Kolb, M. J.; Kwon, Y.; Li, Y.; Koper, M. T. M. J. Am. Chem. Soc. 2013, 135, 14329-14338.

32. Chen, T.; Li, H. J.; Ma, H. Y.; Koper, M. T. M. Langmuir 2015, 31, 3277-3281.

33. Li, H. J.; Li, Y. D.; Koper, M. T. M.; Calle-Vallejo, F. J. Am. Chem. Soc. 2014, 136, 15694-15701.

34. Calle-Vallejo, F.; Koper, M. T. M. Angew. Chem. Int. Ed. 2013, 52, 7282-7285.

35. Skachkov, D.; Rao, C. V.; Ishikawa, Y. J. Phys. Chem. C 2013, 117, 25451-25466.

36. Duca, M.; Figueiredo, M. C.; Climent, V.; Rodriguez, P.; Feliu, J. M.; Koper, M. T. M. J. Am. Chem. Soc. 2011, 133, 10928-10939.

37. Hoffmann, M. J.; Scheffler, M.; Reuter, K. ACS Catal. 2015, 5, 1199-1209.

38. Viswanathan, V.; Hansen, H. A.; Rossmeisl, J.; Jaramillo, T. F.; Pitsch, H.; Nørskov, J. K. J. Phys. Chem. C 2012, 116, 4698-4704.

39. van der Kaap, N. J.; Koster, L. J. A. J. Comput. Phys. 2016, 307, 321-332.

40. Honkala, K.; Hellman, A.; Remediakis, I. N.; Logadottir, A.; Carlsson, A.; Dahl, S.; Christensen, C. H.; Nørskov, J. K. Science 2005, 307, 555-558.

41. Reuter, K. First-principles kinetic Monte Carlo simulations for heterogeneous catalysis: Concepts, status, and frontiers. In Modeling Heterogeneous Catalytic Reactions: From the Molecular Process to the Technical System, 1st ed.; Deutschmann, O., Ed.; Wiley-VCH: Weinberg, 2011; pp 71-111.

42. Exner, K. S.; Anton, J.; Jacob, T.; Over, H. Angew. Chem. Int. Ed. 2016, 55, 7501-7504.

43. Sakong, S.; Groß, A. ACS Catal. 2016, 6, 5575-5586.

44. Wang, V. C. C. Phys. Chem. Chem. Phys. 2016, 18, $22364-22372$.

45. Kresse, G.; Hafner, J. Phys. Rev. B 1993, 47, 558-561.

46. Kresse, G.; Hafner, J. Phys. Rev. B 1994, 49, 14251-14269.

47. Kresse, G.; Furthmuller, J. Phys. Rev. B 1996, 54, 11169-11186.

48. Kresse, G.; Furthmuller, J. Comput. Mater. Sci. 1996, 6, 15-50.

49. Perdew, J. P.; Burke, K.; Ernzerhof, M. Phys. Rev. Lett. 1996, 77, 3865-3868.

50. Kresse, G.; Joubert, D. Phys. Rev. B 1999, 59, 1758-1775.

51. Norskov, J. K.; Rossmeisl, J.; Logadottir, A.; Lindqvist, L.; Kitchin, J. R.; Bligaard, T.; Jonsson, H. J. Phys. Chem. B 2004, 108, 17886-17892.

52. Chase, M. W. NIST-JANAF Thermochemical Tables, 4th ed.; Woodbury: N.Y., 1998.

53. Henkelman, G.; Uberuaga, B. P.; Jonsson, H. J. Chem. Phys. 2000, 113, 9901-9904.

54. Jansen, A. P. J. An Introduction to Kinetic Monte Carlo Simulations of Surface Reactions; Springer: Berlin Heidelberg, 2012. 
55. Reuter, K.; Frenkel, D.; Scheffler, M. Phys. Rev. Lett. 2004, 93, 116105.

56. Reuter, K.; Scheffler, M. Phys. Rev. B 2006, 73, 045433.

57. Ge, Q.; Neurock, M. J. Am. Chem. Soc. 2004, 126, 1551-1559.

58. Gajdos, M.; Hafner, J.; Eichler, A. J. Phys. Condens. Matter 2005, 18, 13-40.

59. Farberow, C. A.; Dumesic, J. A.; Mavrikakis, M. ACS Catal. 2014, 4, 3307-3319.

60. Koper, M. T. M.; Jansen, A. P. J.; van Santen, R. A.; Lukkien, J. J.; Hilbers, P. A. J. J. Chem. Phys. 1998, 109, 6051-6062.

61. Greeley, J.; Mavrikakis, M. J. Am. Chem. Soc. 2004, 126, 3910-3919.

62. Grabow, L. C.; Gokhale, A. A.; Evans, S. T.; Dumesic, J. A.; Mavrikakis, M. J. Phys. Chem. C 2008, 112, 4608-4617.

63. Novell-Leruth, G.; Valcarcel, A.; Clotet, A.; Ricart, J. M.; Perez-Ramirez, J. J. Phys. Chem. B 2005, 109, 18061-18069.

64. Stegelmann, C.; Andreasen, A.; Campbell, C. T. J. Am. Chem. Soc. 2009, 131, 80778082 .

65. Bruna, P. J. Chem. Phys. 1980, 49, 39-52.

66. Bicer, E.; Arat, C. Croat. Chem. Acta 2009, 82, 583-592.

67. Roman, T.; Gross, A. Catal. Today 2013, 202, 183-190.

68. Tse, Y.-L. S.; Knight, C.; Voth, G. A. J. Chem. Phys. 2015, 142, 014104.

69. Zei, M. S.; Ertl, G. Surf. Sci. 1999, 442, 19-26.

70. Wu, K.; Zei, M. S. Surf. Sci. 1998, 415, 212-226.

71. Rossmeisl, J.; Karlberg, G. S.; Jaramillo, T.; Norskov, J. K. Farad. Discuss. 2009, 140, 337-346.

72. Man, I. C.; Su, H.-Y.; Calle-Vallejo, F.; Hansen, H. A.; Martínez, J. I.; Inoglu, N. G.; Kitchin, J.; Jaramillo, T. F.; Nørskov, J. K.; Rossmeisl, J. ChemCatChem 2011, 3, 1159-1165. 73. Herron, J. A.; Ferrin, P.; Mavrikakis, M. J. Phys. Chem. C 2014, 118, 24199-24211. 

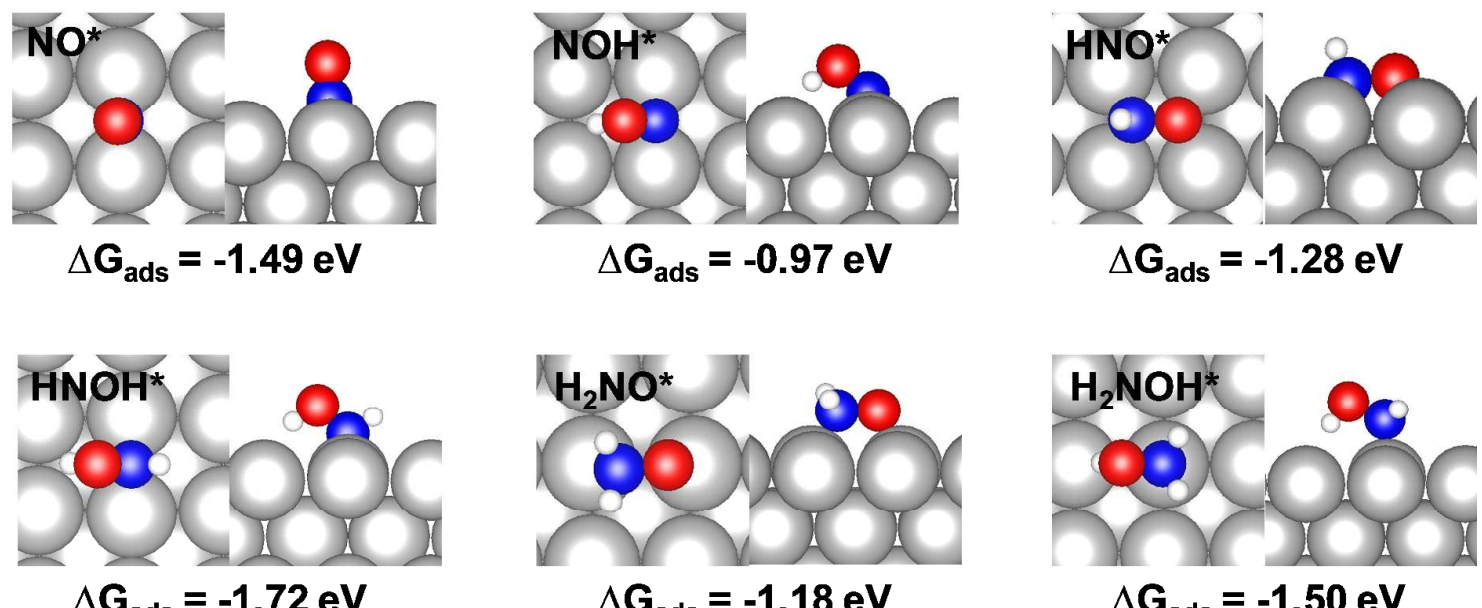

$\Delta \mathbf{G}_{\mathrm{ads}}=-1.18 \mathrm{eV}$

$$
\Delta \mathbf{G}_{\mathrm{ads}}=-1.50 \mathrm{eV}
$$
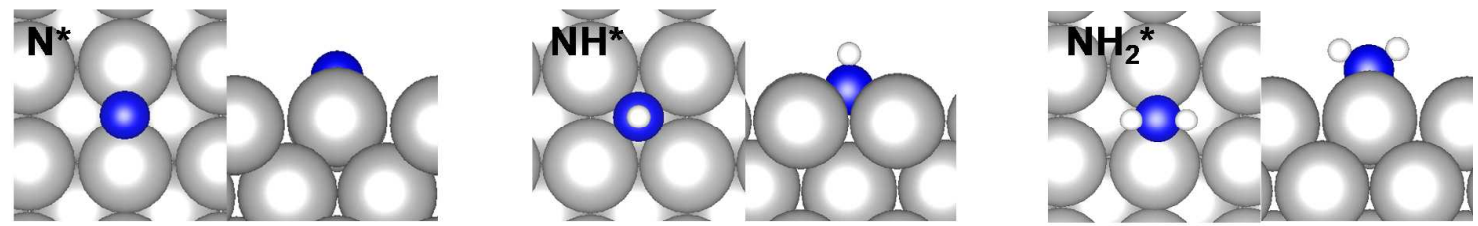

$$
\Delta \mathbf{G}_{\mathrm{ads}}=-\mathbf{2 . 0 4 \mathrm { eV }}
$$

$\Delta \mathbf{G}_{\mathrm{ads}}=\mathbf{- 2 . 8 7 \mathrm { eV }}$

$$
\Delta \mathbf{G}_{\mathrm{ads}}=-\mathbf{3 . 7 1} \mathrm{eV}
$$

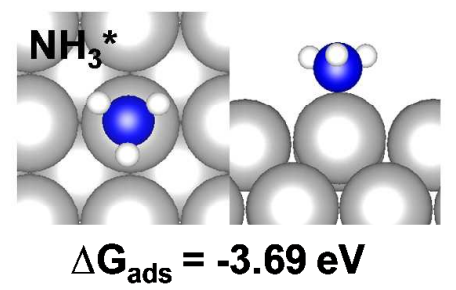

Figure 1. Top and side view of geometries for NO and intermediate species adsorption at $0.11 \mathrm{ML}$ on $\mathrm{Pt}(100)$. The colors represent: grey $=$ platinum, blue $=$ nitrogen, red $=$ oxygen, white $=$ hydrogen. $\Delta \mathrm{G}_{\mathrm{ads}}$ denotes the free energy of each species at $0.0 \mathrm{~V}_{\mathrm{SHE}}$, as determined from Equation 6 in the text. Additional details of the free energy calculations are given in the Supporting Information. 
( ): barriers for vertical HNO*

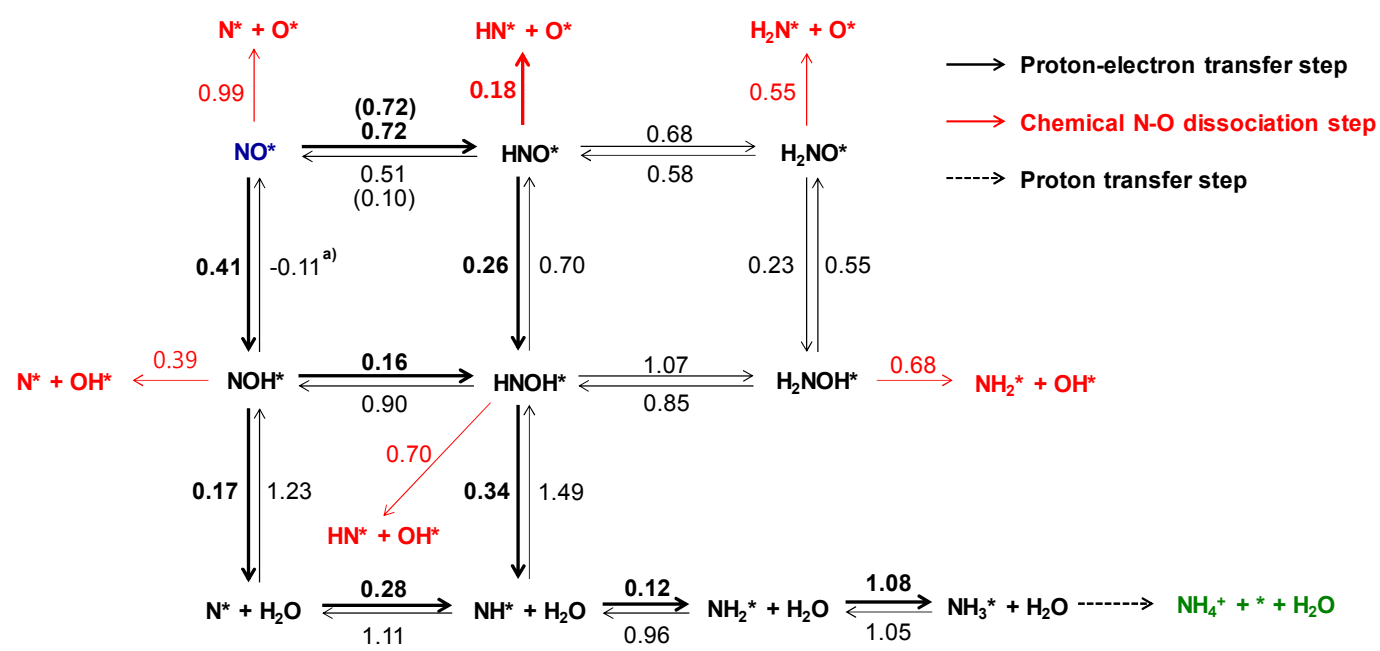

(a)
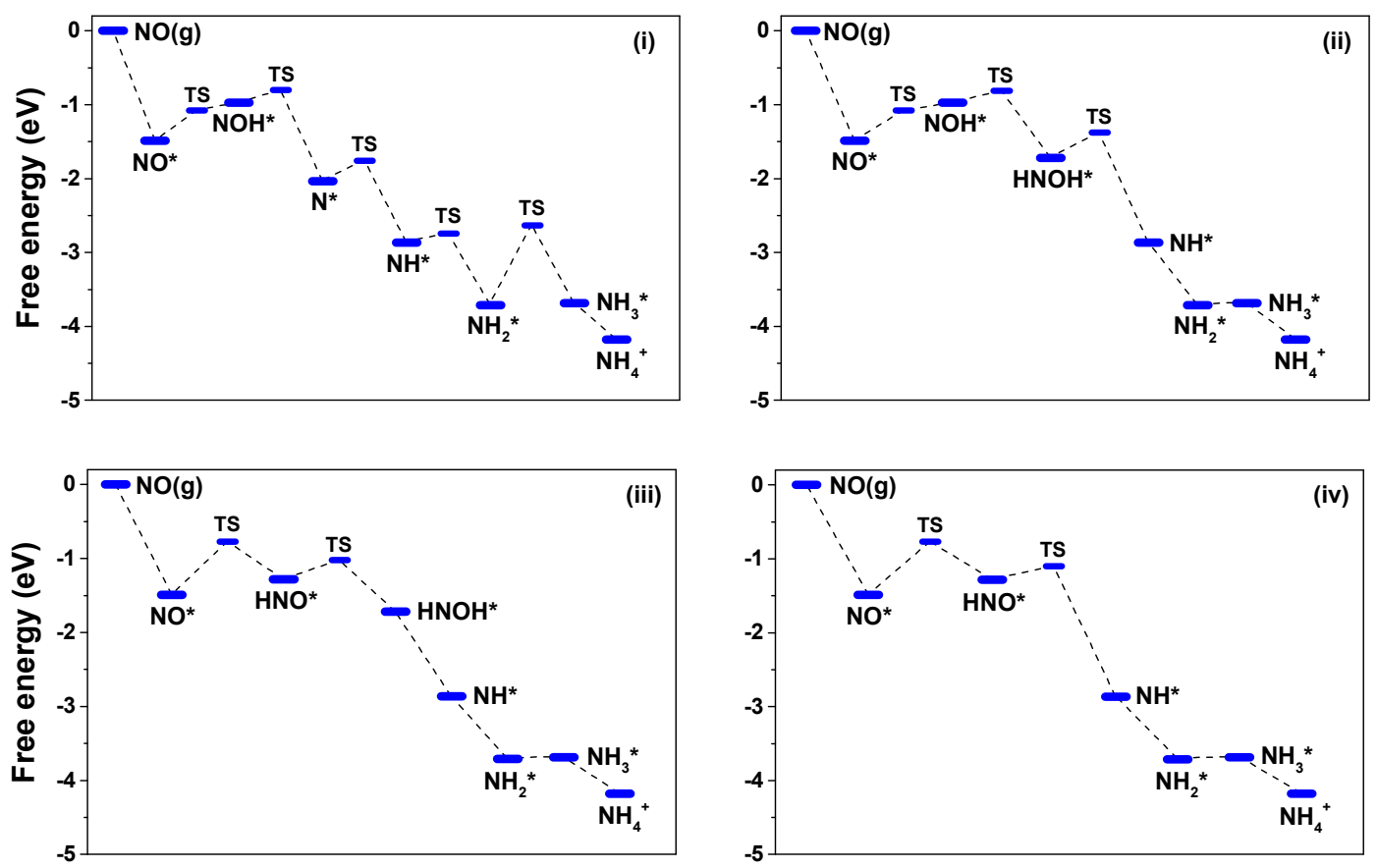

(b)

Figure 2. NO electroreduction on $\operatorname{Pt}(100)$ at $0.11 \mathrm{ML}\left(\mathrm{V}=0.0 \mathrm{~V}_{\mathrm{SHE}}\right)$. (a) The overall reaction network for $\mathrm{NH}_{4}^{+}$ formation. The values represent the forward and reverse activation barriers $(\mathrm{eV})$ for each reaction. Major pathways are shown in bold arrows. Barriers for the horizontal HNO* configuration are shown in standard font, and corresponding values for the tilted $\mathrm{HNO}^{*}$ configuration are in parentheses (see text for additional details). (b) Free energy diagrams for major pathways to $\mathrm{NH}_{4}{ }^{+}$: (i) $\mathrm{NO}^{*} \rightarrow \mathrm{NOH}^{*} \rightarrow \mathrm{N}^{*} \rightarrow \mathrm{NH}^{*} \rightarrow \mathrm{NH}_{2}{ }^{*} \rightarrow \mathrm{NH}_{3}{ }^{*} \rightarrow$ $\mathrm{NH}_{4}^{+}$; (ii) $\mathrm{NO}^{*} \rightarrow \mathrm{NOH}^{*} \rightarrow \mathrm{HNOH}^{*} \rightarrow \mathrm{NH}^{*} \rightarrow \mathrm{NH}_{2}{ }^{*} \rightarrow \mathrm{NH}_{3}^{*} \rightarrow \mathrm{NH}_{4}^{+}$; (iii) $\mathrm{NO}^{*} \rightarrow \mathrm{HNO}^{*} \rightarrow \mathrm{HNOH}^{*} \rightarrow$ $\mathrm{NH}^{*} \rightarrow \mathrm{NH}_{2}{ }^{*} \rightarrow \mathrm{NH}_{3}{ }^{*} \rightarrow \mathrm{NH}_{4}{ }^{+}$; (iv) $\mathrm{NO}^{*} \rightarrow \mathrm{HNO}^{*} \rightarrow \mathrm{NH}^{*} \rightarrow \mathrm{NH}_{2}{ }^{*} \rightarrow \mathrm{NH}_{3}{ }^{*} \rightarrow \mathrm{NH}_{4}^{+}$. Transition states (TS) for the reduction of surface nitrogen species are omitted in (ii), (iii), and (iv).

a) The negative barrier obtained through this model is due to a small energy error (ca $0.2 \mathrm{eV}$ ) in the absence of the full bilayer-water. 


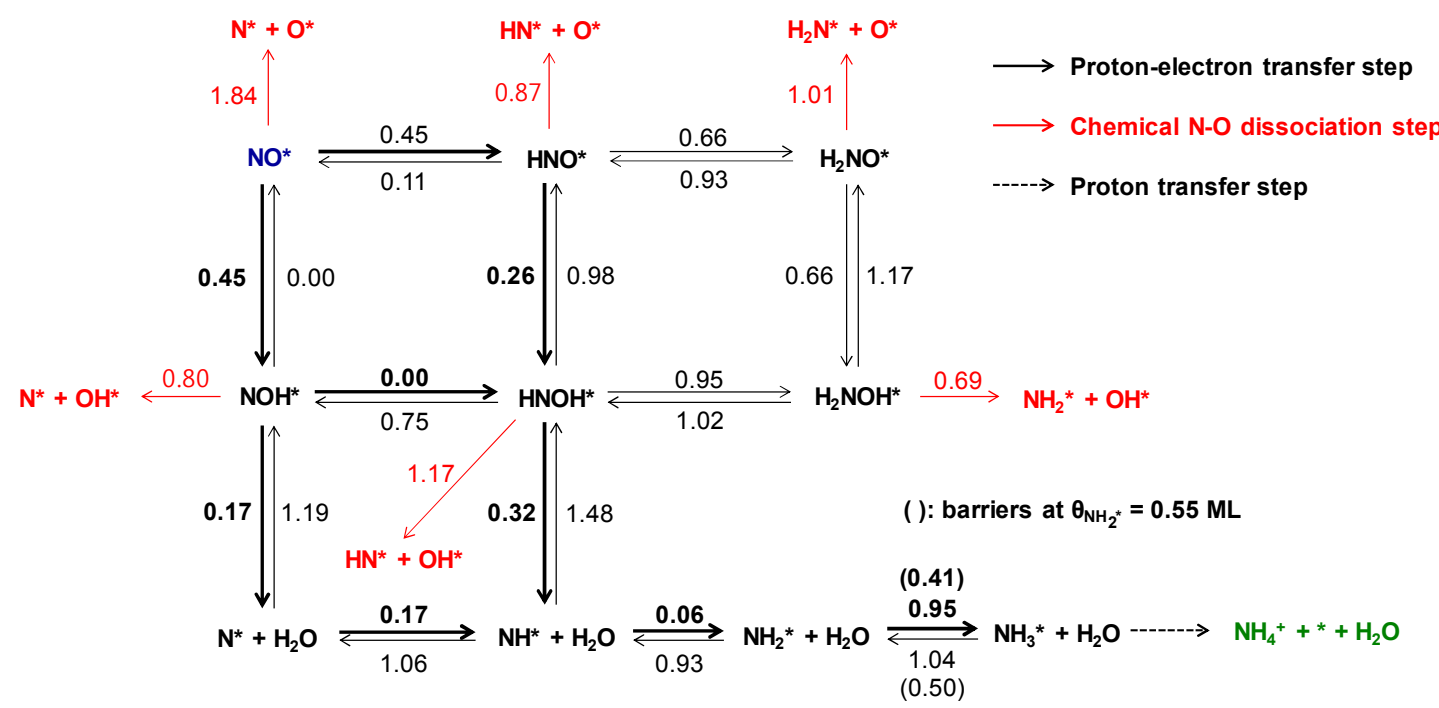

(a)
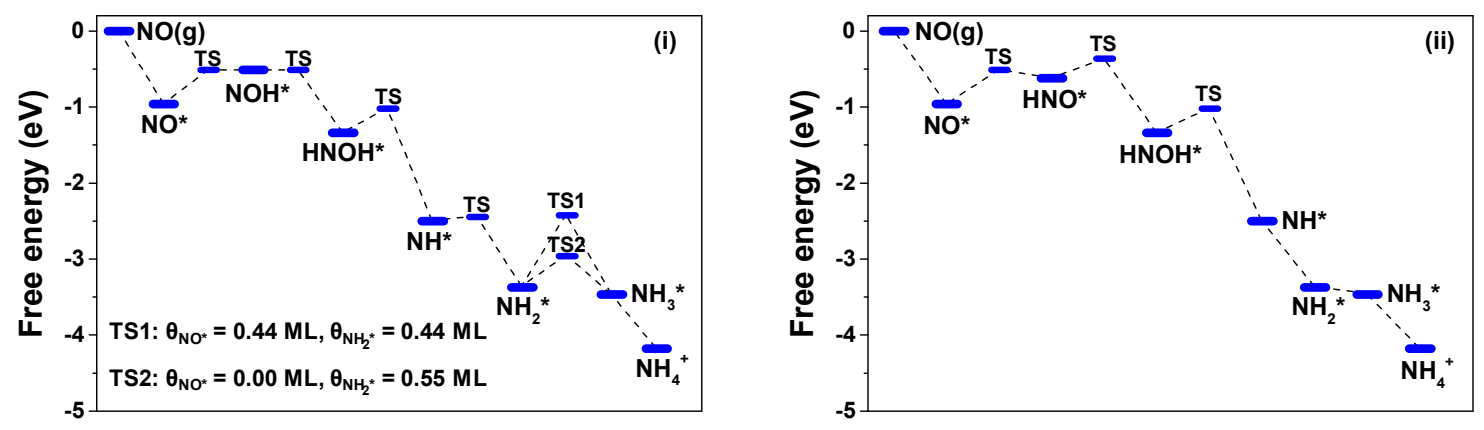

(b)

Figure 3. NO electroreduction on $\mathrm{Pt}(100)$ at $0.55 \mathrm{ML}$ total coverage $\left(\mathrm{V}=0.0 \mathrm{~V}_{\mathrm{SHE}}\right)$. The barrier for $\mathrm{NH}_{2}{ }^{*} \rightarrow$ $\mathrm{NH}_{3} *$ at 0.11 and $0.55 \mathrm{ML}$ of $\mathrm{NH}_{2}{ }^{*}$ coverage are shown. (a) The overall reaction network for $\mathrm{NH}_{4}{ }^{+}$formation. Major pathways are shown in bold arrows. (b) Free energy diagrams for major pathways to $\mathrm{NH}_{4}^{+}$: (i) $\mathrm{NO}^{*} \rightarrow$ $\mathrm{NOH}^{*} \rightarrow \mathrm{HNOH}^{*} \rightarrow \mathrm{NH}^{*} \rightarrow \mathrm{NH}_{2}{ }^{*} \rightarrow \mathrm{NH}_{3}{ }^{*} \rightarrow \mathrm{NH}_{4}^{+}$; (ii) $\mathrm{NO}^{*} \rightarrow \mathrm{HNO}^{*} \rightarrow \mathrm{HNOH}^{*} \rightarrow \mathrm{NH}^{*} \rightarrow \mathrm{NH}_{2}{ }^{*} \rightarrow$ $\mathrm{NH}_{3}{ }^{*} \rightarrow \mathrm{NH}_{4}^{+}$. Transition states (TS) for the reduction of surface nitrogen species are omitted in (ii). 

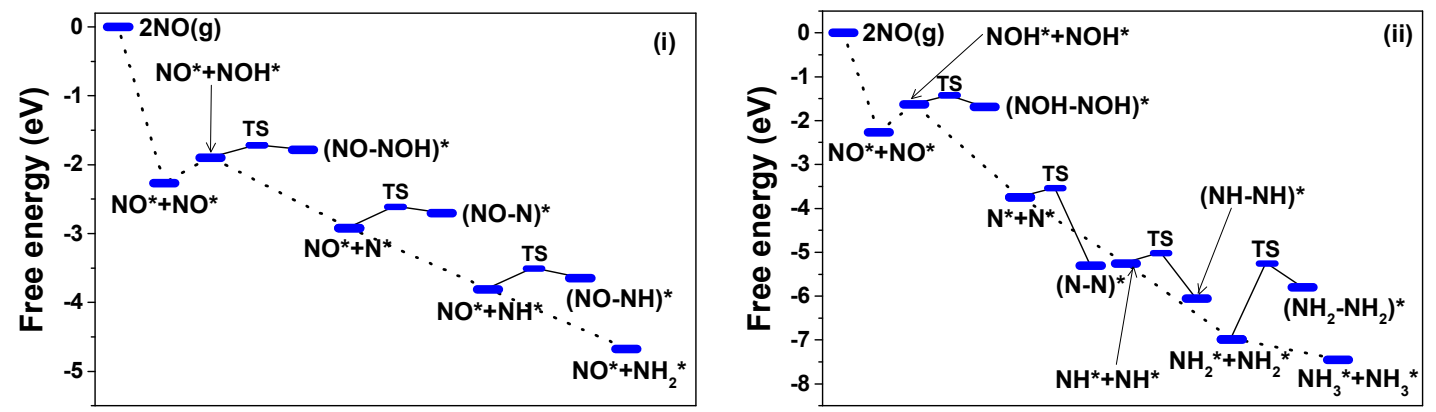

Figure 4. Free energy diagrams for N-N species formation on Pt(100) at $0.55 \mathrm{ML}$. The dotted line represents the protonation pathways (transition states for protonation are not shown but can be found in Figure 3), while the solid line represents the $\mathrm{N}-\mathrm{N}$ bond formation. (i) $\mathrm{N}-\mathrm{N}$ bond formation between $\mathrm{NO}^{*}$ and $\mathrm{NO}_{\mathrm{x} 1} \mathrm{H}_{\mathrm{x} 2}$ * where $\mathrm{x}_{1}=0$, 1 and $\mathrm{x}_{2}=1,2,3$, (ii) $\mathrm{N}-\mathrm{N}$ bond formation through dimerization. 


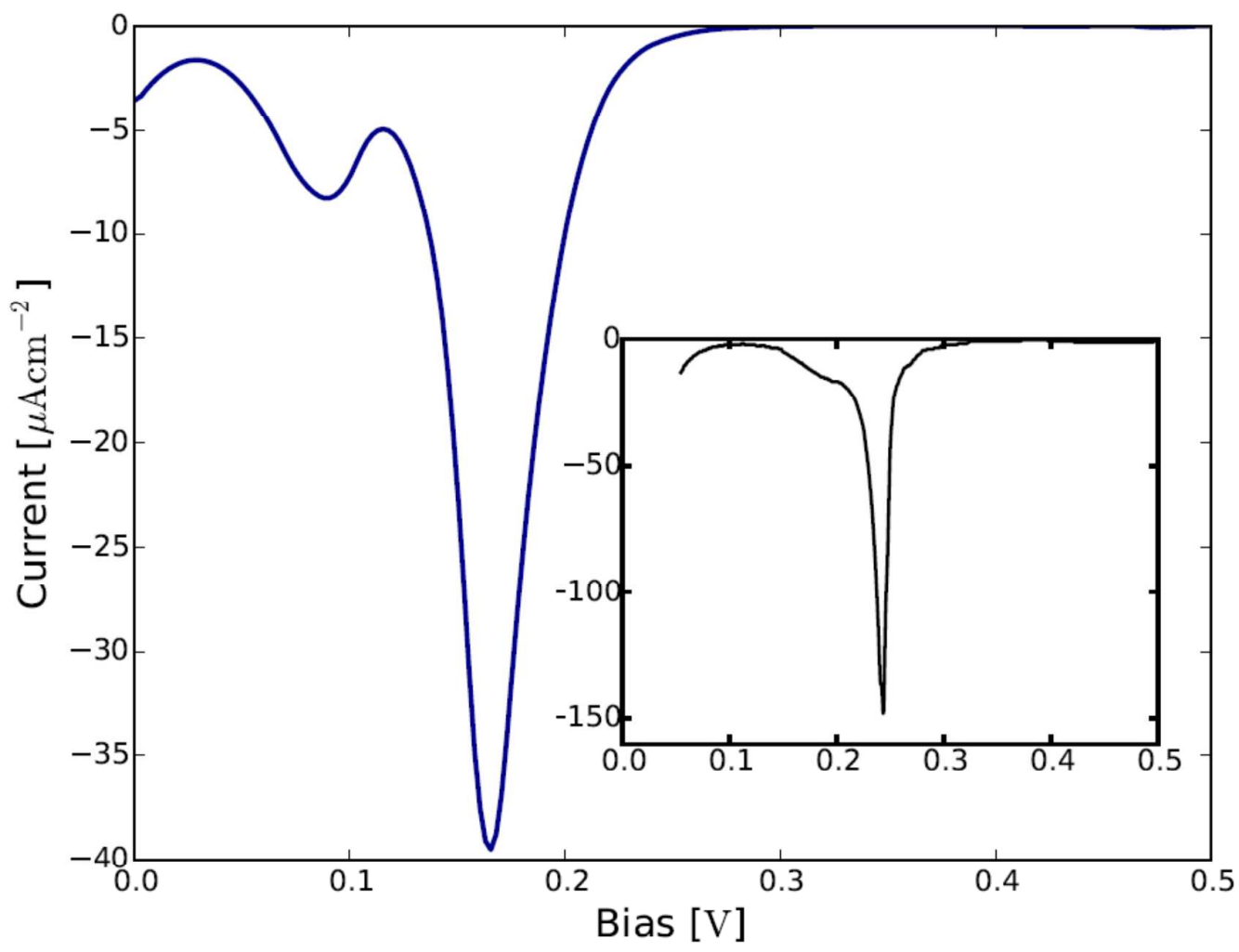

Figure 5: The voltammetric profile for the reductive stripping of NO from the kinetic Monte Carlo simulations at the initial NO coverage of $0.5 \mathrm{ML}$ coverage. The inset gives the experimental profile at the same coverage and sweep rate, extracted from Rosca and Koper. ${ }^{24}$ The units in the experimental figure are the same as in the computed profile. 


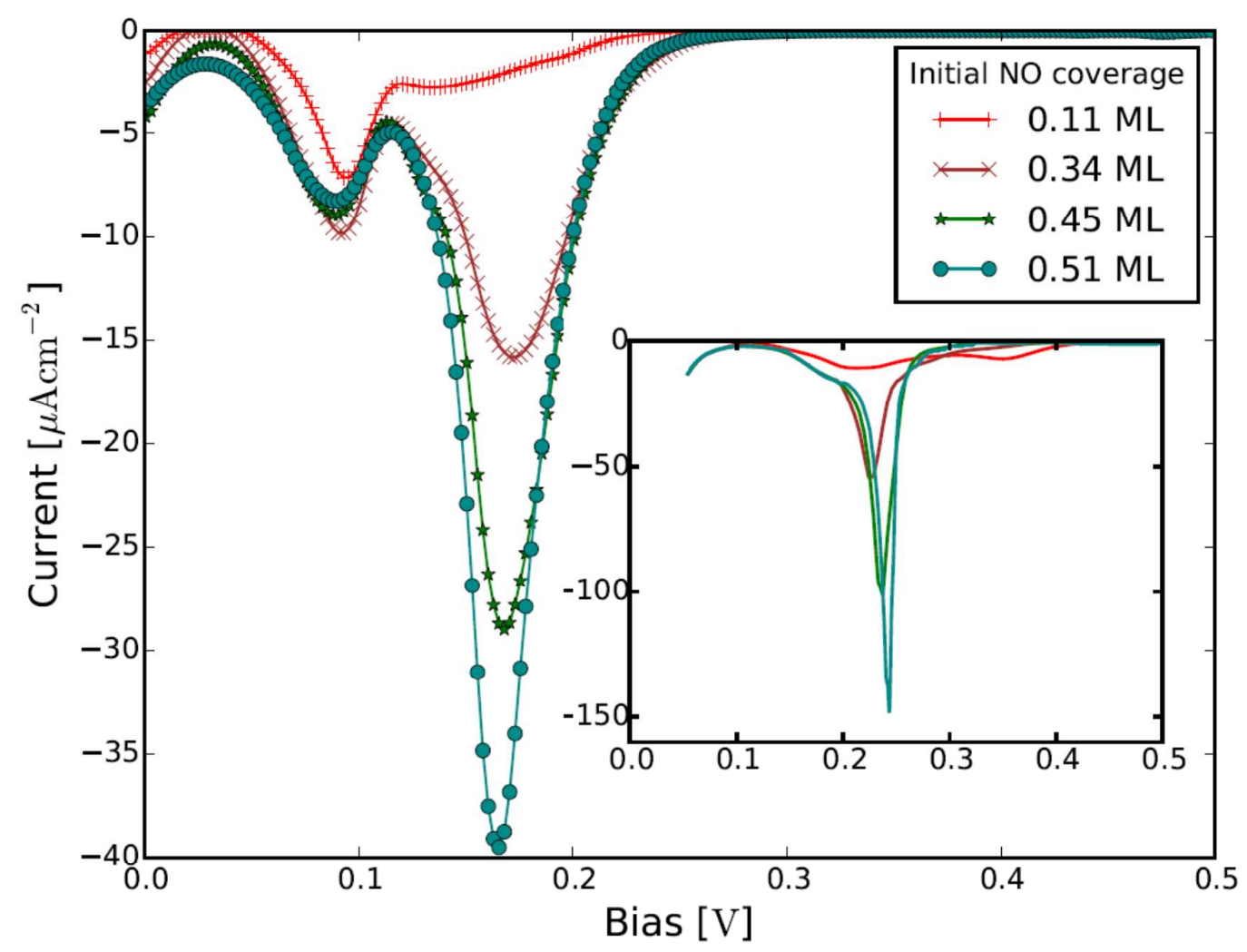

Figure 6: The effect of NO coverage on the voltametric profile for NO electroreduction on $\operatorname{Pt}(100)$. The initial NO coverages are selected as in experiments. The inset gives the measured profiles, which are extracted from ref. ${ }^{24}$ The scan rate both in $\mathrm{kMC}$ simulations and in measurements is $5 \mathrm{mV} / \mathrm{s}$. 


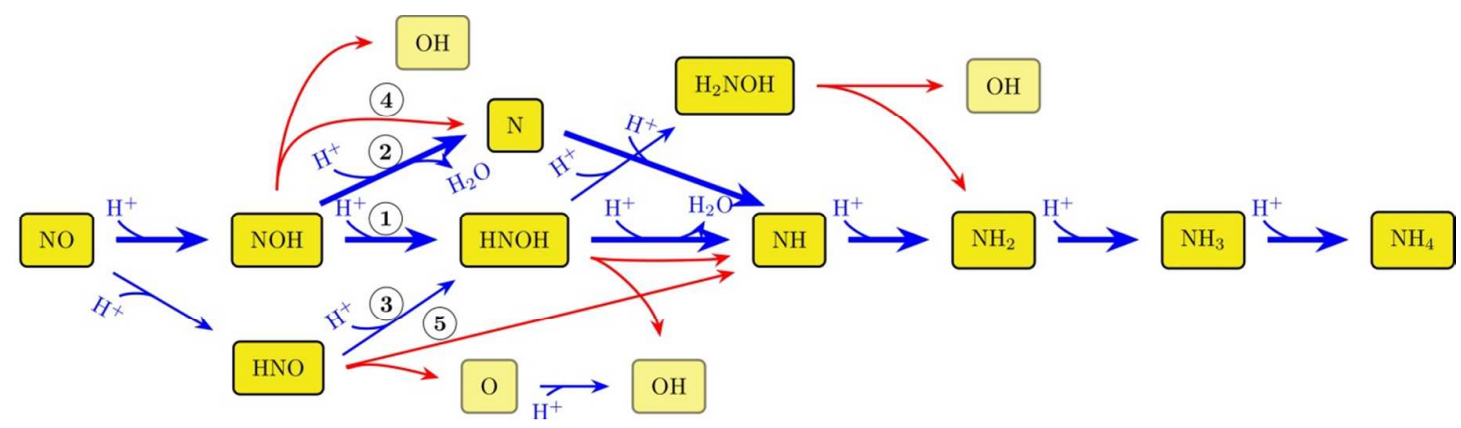

Figure 7: The most probable pathways found in KMC simulations are indicated by numbers within circles. Blue arrows refer to electrochemical steps and red arrows to chemical steps. Thick blue arrows mark the most probable pathways. The circled numbers enumerate the pathways, with the corresponding probabilities listed in Table 1. To simplify the notation, $\left(\mathrm{H}^{+}+\mathrm{e}^{-}\right)$is expressed as $\mathrm{H}^{+}$. 
1

2

3

4

5

6

7

8

9

10

11

12

13

14

15

16

17

18

19

20

21

22

23

24

25

26

27

28

29

30

31

32

33

34

35

36

37

38

39

40

41

42

43

44

45

46

47

48

49

50

51

52

53

54

55

56

57

58

59

60

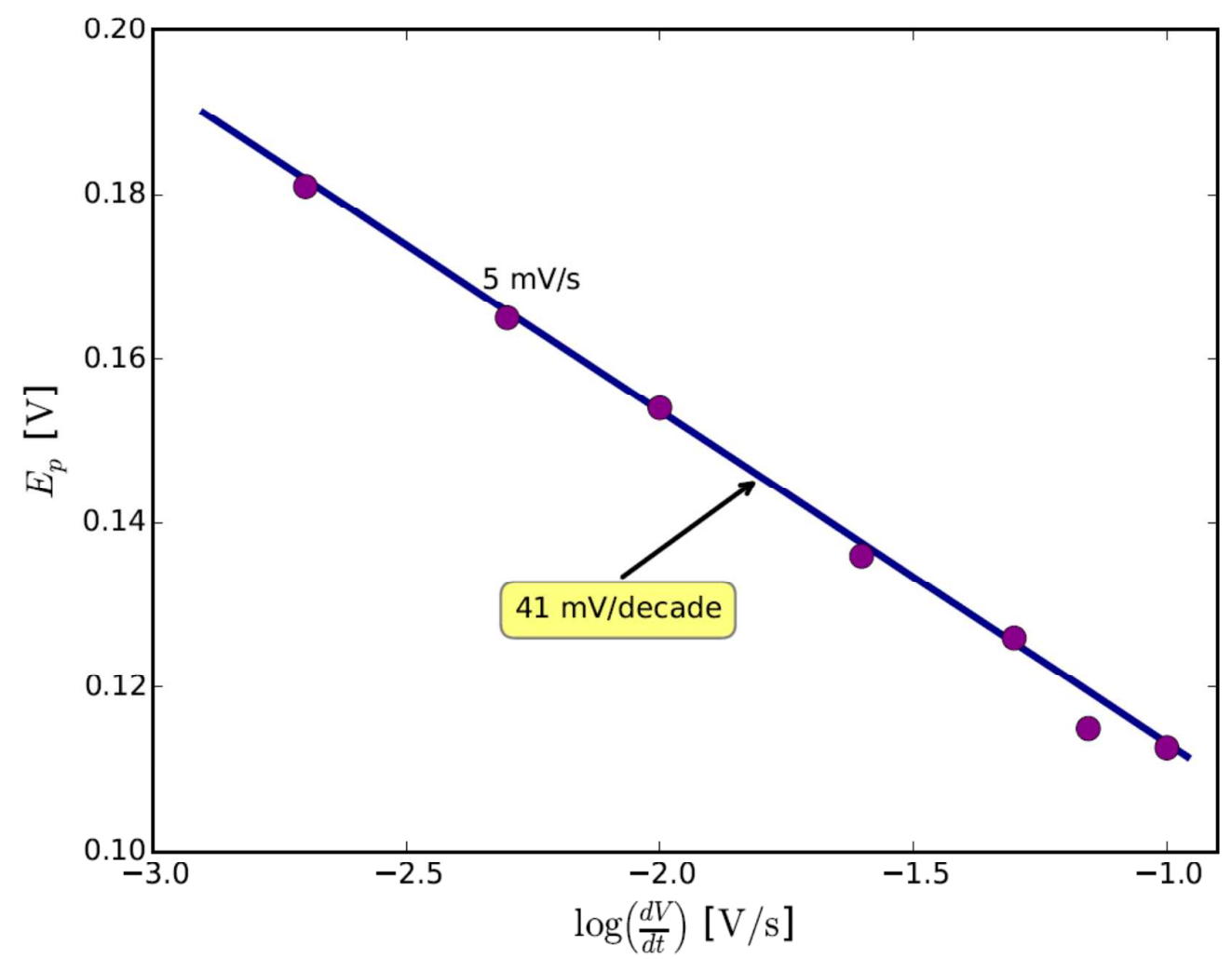

Figure 8: The Tafel slope analysis from kinetic Monte Carlo simulations with sweep rates ranging from 2 to 10 $\mathrm{mV} / \mathrm{s}^{24}$. 
Table 1. Barriers for N-N species via Langmuir-Hinshelwood type mechanism

\begin{tabular}{|c|c|c|c|c|}
\hline \multirow{3}{*}{ N-N species } & \multicolumn{4}{|c|}{$\mathrm{N}-\mathrm{N}$ bond formation barrier $(\mathrm{eV})$} \\
\hline & \multicolumn{2}{|c|}{ Total coverage: $0.22 \mathrm{ML}^{\mathrm{a})}$} & \multicolumn{2}{|c|}{ Total coverage: $0.55 \mathrm{ML}$} \\
\hline & $\mathrm{E}_{\mathrm{a} \_ \text {forward }}$ & $\mathrm{E}_{\mathrm{a} \_ \text {reverse }}$ & $\mathrm{E}_{\mathrm{a} \_}$forward & $\mathrm{E}_{\mathrm{a} \_}$reverse \\
\hline$c i s-(\mathrm{NO})_{2} *$ & n.a. ${ }^{\text {b) }}$ & n.a. & n.a. & n.a. \\
\hline$(\mathrm{NO}-\mathrm{NOH})^{*}$ & 0.56 & 0.06 & 0.18 & 0.07 \\
\hline$(\mathrm{NO}-\mathrm{HNO})^{*}$ & 2.52 & 0.64 & 1.96 & 0.90 \\
\hline$(\mathrm{NOH}-\mathrm{NOH})^{*}$ & 0.42 & 0.24 & 0.20 & 0.27 \\
\hline$(\mathrm{HNO}-\mathrm{HNO})^{*}$ & 3.40 & 1.43 & 2.69 & 1.64 \\
\hline$(\mathrm{NO}-\mathrm{N})^{*}$ & 0.75 & 0.01 & 0.31 & 0.09 \\
\hline$(\mathrm{NO}-\mathrm{NH})^{*}$ & 0.72 & 0.08 & 0.30 & 0.14 \\
\hline$\left(\mathrm{NO}-\mathrm{NH}_{2}\right)^{*}$ & n.a. & n.a. & n.a. & n.a. \\
\hline$\left(\mathrm{NO}-\mathrm{NH}_{3}\right)^{*}$ & n.a. & n.a. & n.a. & n.a. \\
\hline$(\mathrm{N}-\mathrm{N})^{*}$ & 0.85 & 1.59 & 0.21 & 1.76 \\
\hline$(\mathrm{NH}-\mathrm{NH})^{*}$ & 0.50 & 0.85 & 0.24 & 1.03 \\
\hline$\left(\mathrm{NH}_{2}-\mathrm{NH}_{2}\right)^{*}$ & 2.26 & 0.38 & 1.73 & 0.55 \\
\hline$\left(\mathrm{NH}_{3}-\mathrm{NH}_{3}\right)^{*}$ & n.a. & n.a. & n.a. & n.a. \\
\hline
\end{tabular}

a) Coverage denotes the total coverage of surface adsorbates including NO and the other species.

b) Corresponding species is not detected on $\mathrm{Pt}(100)$. Geometry optimization of this structure on the flat surface yields two separated species at adjacent sites, but no bond is formed between the two $\mathrm{N}$ atoms. 
Table 2: Calculated probabilities for reaction through different NO electroreduction pathways at various initial NO coverages. The probabilities are obtained by analyzing at least $45 \mathrm{kMC}$ simulations for each coverage, and the number of path samples is between $\sim 7000$ (for $0.51 \mathrm{ML}$ coverage) to $\sim 300$ (for $0.11 \mathrm{ML}$ coverage). The numbering of the pathways is taken from Figure 8 . The pathway * refers to a pathway where $\mathrm{HNOH}^{*}$ (formed from $\mathrm{NOH}^{*}$ ) chemically dissociates to $\mathrm{NH}^{*}$ and $\mathrm{OH}^{*}$ and then forms ammonia and water. This pathway does not appear at other initial NO coverages. Conversely, pathway 3 does not occur for $0.11 \mathrm{ML}$ coverage.

\begin{tabular}{|c|c|c|}
\hline $\begin{array}{l}\text { initial } \Theta_{\mathrm{NO}} \\
(\mathrm{ML})\end{array}$ & $\begin{array}{c}\text { Probability of the } \\
\text { pathway }(\%)\end{array}$ & $\begin{array}{c}\text { Pathway } \\
\text { (see Figure 8) }\end{array}$ \\
\hline \multirow{5}{*}{0.51} & 55.4 & 1 \\
\hline & 37.9 & 2 \\
\hline & 5.62 & 3 \\
\hline & 0.66 & 4 \\
\hline & 0.40 & 5 \\
\hline \multirow{5}{*}{0.45} & 56.1 & 1 \\
\hline & 39.7 & 2 \\
\hline & 3.05 & 3 \\
\hline & 0.72 & 4 \\
\hline & 0.42 & 5 \\
\hline \multirow{5}{*}{0.35} & 56.4 & 1 \\
\hline & 40.5 & 2 \\
\hline & 1.53 & 3 \\
\hline & 0.80 & 4 \\
\hline & 0.74 & 5 \\
\hline \multirow{5}{*}{0.11} & 61.09 & 1 \\
\hline & 36.01 & 2 \\
\hline & 2.25 & 5 \\
\hline & 0.32 & 4 \\
\hline & 0.32 & $*$ \\
\hline
\end{tabular}




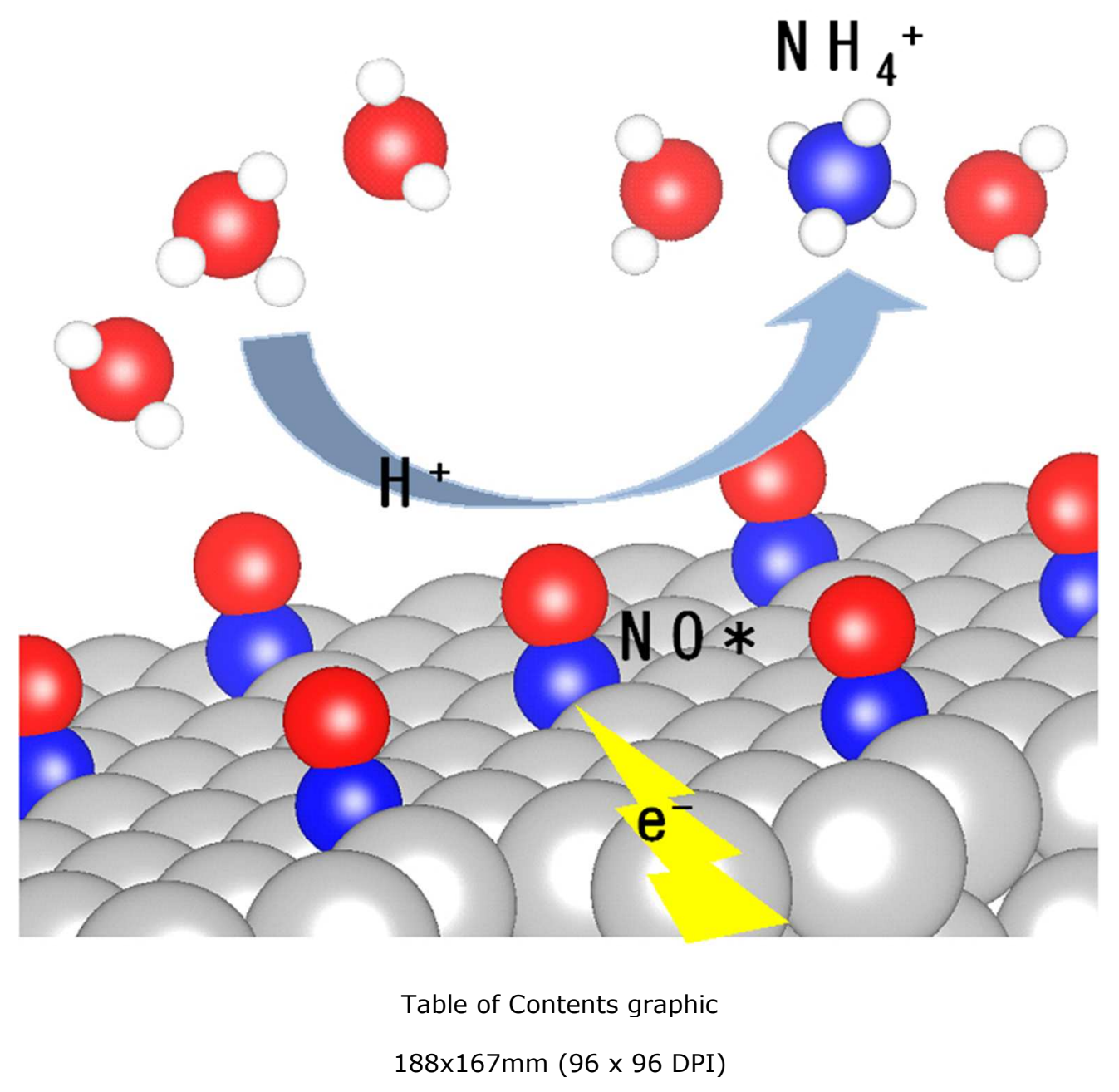

42

43

44

45

46

47

48

49

50

51

52

53

54

55

56

57

58

59

60 